\title{
Römische Kriegsdeutungen und römische Kriegführung im früheren Mittelalter
}

Sie ist in eine Toga gekleidet, trägt aber keine Tunika, sodass ihre entblößten Arme sichtbar bleiben. Ihr Gesicht wirkt mit einer Knollennase und den kurzen Locken, die den Kopf kaum bedecken, männlich, ja kriegerisch. Dieser Eindruck wird unterstrichen, da die Gestalt in der Linken eine Lanze hält, im Gürtel ein Schwert trägt und sich mit der Rechten auf einen steil aufgerichteten spitzovalen Buckelschild stützt. Der Kopfschmuck endet in drei Federn, die Füße erscheinen hingegen unbeschuht. Die nimbierte Figur sitzt leicht zur linken Seite gewandt auf einem Kastenthron. Hinter ihr befindet sich eine kreuzförmige Architektur auf hellem Grund. In Kapitalschrift steht dort die Buchstabengruppe ROMA niedergeschrieben, welche dem Betrachter die Entschlüsselung der abgebildeten Gestalt ermöglicht: Es handelt sich um die wehrhafte Stadt Rom. Der Dichter Vergil hat dem Leitmotiv des kampfesmutigen Römers einst in der »Aeneis« mit unvergessenen Worten Ausdruck verliehen. Sie lauten:

"Du aber, Römer, denke, die Völker mit Deiner Herrschaft zu lenken, darin liegt Dein Beruf. Stifte Ordnung dem Frieden, schone, wer gehorsam sich fügt, und brich im Kriege der Rebellen Trotz ${ }^{1} !_{\ll}$

Das erwähnte Bild zählt zu einer kurzen, aber einprägsamen Reihe von Stadt- und Herrscherpersonifikationen, die aus der Spätantike bekannt ist. Es geht einer Abschrift der »Notitia urbis Romae« voraus. Eine ähnliche Stadtpersonifikation gehörte vermutlich zu einem Prachtcodex, den der Caesar Valentinian III. um das Jahr 425 während oder nach seiner Mitkaiserkrönung entgegengenommen hat ${ }^{2}$. Die bildliche Darstellung verlieh der Stadt Rom den Charakter, den Zeitgenossen und Nachgeborene seit jeher mit ihr verbinden und den auch der vorliegende Aufsatz thematisiert. Es geht nachfolgend um die Weitervermittlung bestimmter Techniken und Deutungsmuster des Krieges aus der römischen Antike in das frühere Mittelalter.

1 Verg., Aen. 6, 851-853: Tu regere imperio populos, Romane, memento / Hae tibi erunt artes pacique imponere morem / Parcere subiectis et debellare superbos.

2 München, Bayerische Staatsbibliothek: Clm 10291, fol. 177r; Jonathan J.G. Alexander, The Illustrated Manuscripts of the Notitia Dignitatum. In: Aspects of the Notitia Dignitatum. Papers Presented to the Conference in Oxford, December 13 to 15, 1974. Ed. by Roger Goodburn and Philip Bartholomew, Oxford 1976 (= British Archaeological Reports, Supplementary Series, 15), S. 11-49, bes. Tafel 21; Ndr. in: Jonathan J.G. Alexander, Studies in Italian Manuscript Illumination, London 2002, S. 65-98, S. 385 f., bes. Abb. 26; zur prächtigen Ausstattung der spätantiken Vorlage als Hinweis auf das kaiserliche Milieu, eventuell sogar Ravenna, als Entstehungsort: Pamela C. Berger, The Insignia of the "Notitia Dignitatum ", New York, London 1981 (= Outstanding Dissertations in the Fine Arts), S. 158-167, 172 f.; zu Stadt- und Herrscherpersonifikationen der Spätanike: Andreas Alföldi, Hasta - Summa Imperii. The Spear as Embodiment of Sovereignty in Rome. In: American Journal of Archeology, 63 (1959), S. 1-27; Andreas Alföldi, Die monarchische Repräsentation im römischen Kaiserreiche. Mit Register von Elisabeth Alföldi-Rosenbaum, 2. Aufl., Darmstadt 1970, S. 161-186 (Erstausgabe 1935); Robert Grigg, Portrait-bearing 


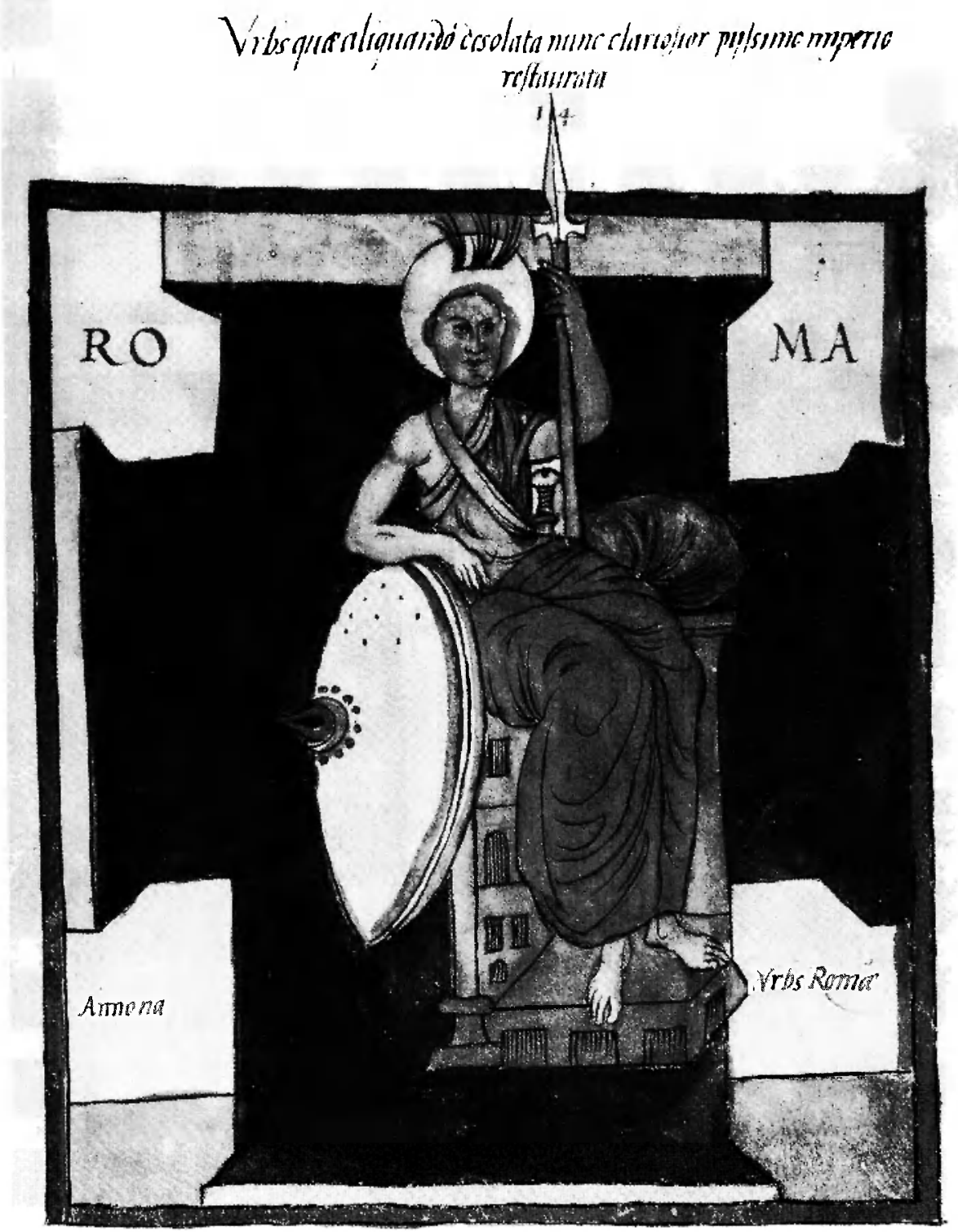

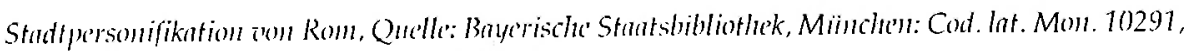
fol. 177r; Hendschrift inen 1.542 bzal. 1550/51. 
Das Fortwirken der römischen Kriegführung und der römischen Kriegsdeutungen zwischen dem 5. und 9. Jahrhundert lässt sich zum einen mit Blick auf die realen Veränderungen ${ }^{3}$, zum anderen unter Berücksichtigung der Aussagen der schriftlichen Quellen nachvollziehen. Weiter unten wird von ausgewählten lateinischen Quellen der römischen Kaiserzeit ausgegangen, um von hier aus einige Spuren des Weiterlebens römischer Ideen und römischer Lebensvollzüge im früheren Mittelalter weiterzuverfolgen. Als eigentliches Betrachtungsfeld werden dabei die Kriegführung und die Kriegsdeutungen gewählt, da sie neben dem Recht und der Dichtung am ehesten als römische Besonderheiten gelten dürfen ${ }^{4}$.

Codicils in the Illustrations of the "Notitia Dignitatum«. In: JRS, 69 (1979), S. 107-124, bes. S. 107-110; Gudrun Bühl, Constantinopolis und Roma. Stadtpersonifikationen der Spätantike, Zürich 1995, S. 254-265, bes. S. 264 f.; mir nicht zugänglich war: Concepción Neira Faleiro, La plenitudo potestatis e la veneratio imperatoris come principio dogmatico della politica della tarda Antichità. Un chiaro esempio: la "Notitia dignitatum «. In: The Representation and Perception of Roman Imperial Power. Proceedings of the Third Workshop of the International Network Impact of Empire (Roman Empire 200 B.C.-A.D. 476), Netherlands Institute in Rome, March 20-23, 2002. Ed. by Lukas de Blois [u.a.], Amsterdam 2004, S. 170-185.

3 Hans Delbrück, Geschichte der Kriegskunst im Rahmen der politischen Geschichte, 2 Bde, Berlin 1900-1902; Alfred Alföldi, Studien zur Geschichte der Weltkrise des 3. Jahrhunderts nach Christus, Darmstadt 1967, S. 394-416; Arnold Hugh Martin Jones, The Later Roman Empire, 284-602. A Social, Economic, and Administrative Survey, vol. 2, Oxford 1964, S. 607-686; Michael Grant, Das Römische Reich am Wendepunkt. Die Zeit von Mark Aurel bis Konstantin, München 1984, S. 15-52; Philippe Contamine, La guerre au moyen age, 4. ed., Paris 1994, S. 71-97; Hugh Elton, Warfare in Roman Europe, A.D. 350-425, Oxford 1996.

4 Zur Kriegführung: Theodor Mommsen, Das römische Heerwesen seit Diocletian. In: Hermes, 24 (1889), S. 195-279; Robert Grosse, Römische Militärgeschichte von Gallienus bis zum Beginn der byzantinischen Themenverfassung, Berlin 1920; Denis van Berchem, L'armée de Dioclétien et la réforme constantinienne, Paris 1952 (= Bibliothèque archéologique et historique, 56); Chester G. Starr, The Roman Imperial Navy, 31 B.C.-A.D. 324, 2. ed., Cambridge 1960, 3. ed., Chicago 1993; Dietmar Kienast, Untersuchungen zu den Kriegsflotten der römischen Kaiserzeit, Bonn 1966 (= Antiquitas, Reihe 1, 13); Eric W. Marsden, Greek and Roman Artillery. Technical Treatises, Oxford 1971; Clifford Edward Minor, Brigand, Insurrectionist and Seperatist Movements in the Later Roman Empire, Ph.D. Washington 1971 (= Ann Arbor, Michigan University Microfilms); Michel Reddé, Mare nostrum. Les infrastructures, le dispositif, et l'histoire de la marine militaire sous l'Empire Romain, Roma 1986 (= Bibliothèque des Écoles Françaises d'Athènes et de Rome, 260); Jonathan P. Roth, The Logistics of the Roman Army at War (264 B.C.-A.D. 235), Leiden, Boston, Köln 1999 (= Columbia studies in classical tradition, 23); Peter Kehne, Zur Logistik des römischen Heeres von der mittleren Republik bis zum Ende der hohen Kaiserzeit (241 v.Chr.-235 n.Chr.). Forschungen und Tendenzen. In: MGZ, 63 (2004), S. 115-152; zu Kriegsdeutungen: Jörg Rüpke, Domi militiae. Die religiöse Konstruktion des Krieges in Rom, Stuttgart 1990; War and Society in the Roman World. Ed. by John W. Rich and Graham Shipley, London, New York 1993 (= Leicester Nottingham Studies in Ancient Society, 5); Michaela Kostial, Kriegerisches Rom? Zur Frage von Unvermeidbarkeit und Normalität militärischer Konflikte in der römischen Politik, Stuttgart 1995 (= Palingenesia, 55); Jörg Rüpke, Wege zum Töten, Wege zum Ruhm. Krieg in der römischen Republik. In: Töten im Krieg. Hrsg. von Heinrich von Stietencron und Jörg Rüpke, München 1995 (= Veröffentlichungen des Instituts für historische Anthropologie, 6), S. 213-240 (mit weiterer Literatur). Begonnen von Marilyn C. Bishop, erscheinen regelmäßig die "Proceedings of the International Roman Military Equipment Conference", die neuesten unter dem Titel: Re-Enactment as Research. Proceedings of the Twelfth International Roman Military Equipment Conference, held at South Shields, 1999. Ed. by Alexander T. Croom, Braemar 2002 (= Journal of Roman Military Equipment Series, 11). 
, 
von Städten oder an den Außengrenzen des Reiches ${ }^{17}$ wie in den verschiedenen Formen der Land- und Besitzteilung ${ }^{18}$ oder auch in den zahlreichen Umstrukturierungen der römischen Armee, die seit dem.3. Jahrhundert einsetzten und auch in der Folgezeit Auswirkungen zeitigten ${ }^{19}$, gesehen. Die römische Militärtradition im engeren Sinne wurde im Mittelalter allerdings nur im byzantinischen Osten fortgeführt ${ }^{20}$, während sie im Westen im Verlauf des 5 . Jahrhunderts abbrach.

Der vorliegende Aufsatz folgt einem vorstellungsgeschichtlichen Ansatz, indem er bevorzugt erzählende Quellen analysiert. Hierzu zählen Briefe, Reformtraktate, Militärhandbücher, Enzyklopädien, Volksgeschichten, liturgische Ordines, eine Lamentatio, Epen und Lieder. Hinzu kommen Bilder in Handschriften und eine Truppenliste. Auf dieser Grundlage wird die literarische Vermittlung von Deutungsschemata betrachtet, indem zunächst die handschriftliche Überlieferung mehrerer lateinischer Militärschriftsteller schlaglichtartig beleuchtet, sodann an einigen Aspekten die Verwendung dieser Quellen im Rahmen der karolingischen Renaissance dargelegt und ferner auf die militärtechnische Tradition im byzantinischen Osten eingegangen wird. An Hand ausgewählter Quellen werden anschließend römische Kriegsdeutungen und römische Kriegführung im Verhältnis zu ihrem jeweiligen (christlichen oder germanischen) Gegenüber erörtert. Die Darstellung endet mit einem Resümee zu den militärgeschichtlichen Aussagen, dem Gebrauch und den Wahrnehmungsmustern, die die behandelten Quellen verdeutlichen.

17 Zu Stadtbefestigungen: Stephen Johnson, Late Roman Fortifications, London, Totowa, NJ 1983; Bernard S. Bachrach, Imperial Walled Cities in the West and Their Early Medieval Nachleben. In: City Walls. The Urban Enceinte in Global Perspective. Ed. by James D. Tracy, Cambridge 2000 (= Studies in Comparative Early Modern History, 4), S. 198-218; zu Grenzbefestigungen: Alfred Rüsch, Arae Flaviae. Die Militärlager und die Zivilsiedlung in Rottweil am Necker. In: ANRW, II 5/1 (1976), S. 560-600; Harald von Petrikovits, Fortifications in the North-Western Roman Empire from the Third to the Fifth Centuries A.D. In: JRS, 61 (1971), S. 178-218; Nicolae Gudea, Der Limes Dakiens und die Verteidigung der obermosesischen Donaulinie von Trajan bis Aurelian. In: ANRW, II 6 (1977), S. 849-887; Jürgen Oldenstein, Die letzten Jahrzehnte des römischen Limes zwischen Andernach und Selz unter besonderer Berücksichtigung des Kastells Alzey und der "Notitia Dignitatum«. In: Zur Kontinuität (wie Anm. 16), S. 69-112 sowie Abb. 1-5.

18 Grant, Das Römische Reich (wie Anm. 3), S. 45 f.; Beat Meyer-Flügel, Das Bild der ostgotisch-römischen Gesellschaft bei Cassiodor. Leben und Ethik von Römern und Germanen in Italien nach dem Ende des Weströmischen Reiches, Bern [u.a.] 1992 (= Europäische Hochschulschriften, Reihe 3, 533), S. 120-123.

19 Brian Dobson, The Significance of the Centurion and »Primipilaris in the Roman Army and Administration. In: ANRW, II 1 (1974), S. 392-434; Alexander C. Murray, From Roman to Frankish Gaul. Centenarii and Centenae in the Administration of the Merovingian Kingdom. In: Traditio, 44 (1988), S. 60-100; Bernard S. Bachrach, The Imperial Roots of Merovingian Military Organization. In: Military Aspects of Scandinavian Society in a European Perspective, A.D. 1-1300. Ed. by Anne Norgard Jorgensen and Birthe L. Clausen, Kopenhagen 1997, S. 25-31.

20 John F. Haldon, Recruitment and Conscription in the Byzantine Army, c. 550-950. A Study on the Crisis of the "stratioka ktemata«, Wien 1979 (= SAW, PH, 357); Warren Treadgold, Byzantium and Its Army, 284-1081, Stanford, CA 1995. 


\section{Die handschriftliche Überlieferung der klassischen Militärschriftsteller}

Die wichtigsten Werke zur römischen Kriegführung ${ }^{21}$, die von so prominenten Autoren wie Caesar ${ }^{22}$, Cicero ${ }^{23}$, Sallust ${ }^{24}$, Livius ${ }^{25}$, Tacitus $^{26}$, Vergil ${ }^{27}$, Frontin ${ }^{28}$ oder Vegez ${ }^{29}$ stammen oder wie die $»$ Notitia dignitatum ${ }^{30}$ und die Reformschrift $» D e$ rebus bellicis « ${ }^{31}$ der Nachwelt aus eher zufälligen Gründen erhalten geblieben wa-

Überblick über antike Kriegsberichte und -abhandlungen: Hans-Joachim Diesner, Kriege des Altertums. Griechenland und Rom im Kampf um den Mittelmeerraum, Berlin 1985 (= eurobuch, 20), S. 224-242.

22 Virginia Brown, (Art.) Caesar im Mittelalter B. In: LMA, Bd 2, München, Zürich 1983, Sp. $1353 \mathrm{f}$.

23 Paolo Fedeli, Il „De officiis« di Cicerone. Problemi e atteggiamenti della critica moderna. In: ANRW, I 4 (1973), S. 357-427, bes. S. 376-387; mir nicht zugänglich war: N.E. Nelson, Cicero's De officiis in Christian Thought: 300-1300. In: Language and Literature, 10 (1933), S. 59-160.

24 Salluste. Catilina. Jugurtha. Fragments des histoires. Texte établi et trad. par Alfred Ernout, Paris 1974 (= Collection des universités de France), S. 37-50, bes. S. 37 f., 50; Anna-Dorothee van den Brincken, Mappa mundi. In: Monumenta Annonis. Köln und Siegburg. Weltbild und Kunst im hohen Mittelalter. Eine Austellung des Schnütgen-Museums der Stadt Köln in der Cäcilienkirche vom 30. April bis zum 27. Juli 1975. Hrsg. von Anton Legner, Köln 1975, S. 112-119, bes. S. 112 (Überlieferung von Sallust zusammen mit so genannten T-Karten).

Franz Brunhölzl, (Art.) Livius, Titus. In: LMA, Bd 5, München, Zürich 1991, Sp. 2943 f.

26 Franz Brunhölzl, (Art.) Tacitus I. In: Ebd., Bd 8, München, Zürich 1997, Sp. 400 f.

27 Publius Vergilus Maro, Opera. Ed. by Roger Aubrey Baskerville Mynors, Oxford 1969, S. V-XIII, XVI, bes. S. V-VII; Pierre Courcelle, Les lecteurs de l' "Éneide " devant les grandes invasions germaniques. In: Romanobarbarica, 1 (1976), S. 25-56; Maria Klippel, Die Darstellung der Trojanersage in Geschichtsschreibung und Dichtung vom Mittelalter bis zur Renaissance in Frankreich, Diss. phil. Marburg 1936; Paul Klopsch, (Art.) Vergil im Mittelalter. In: LMA, Bd 8, München, Zürich 1997, Sp. 1522-1526.

${ }_{28}$ Julius Frontinus, Strategemata. Hrsg. von Robert I. Ireland, Leipzig 1990 (= Bibliotheca scriptorum Graecorum et Romanorum Teubneriana), S. XXXIII (drei Codices aus dem 9. Jh.).

29 Publius Flavius Vegetius, Epitome rei militaris. Hrsg. von Alf Önnerfors, Stuttgart, Leipzig 1995; Publius Flavius Vegetius, Abriß des Militärwesens. Übers. von Friedhelm Müller, Stuttgart 1997.

30 Ausgaben: Notitia dignitatum et administrationum omnium tam civilium quam militarium in partibus Orientis et Occidentis. Hrsg. von Eduard Böcking, 4 Bde, Bonn 1839, 1849, 1850, 1853; Notitia Dignitatum accedunt Notitia urbis Constantinopolitanae et Latercula prouinciarum. Hrsg. von Otto Seeck, Berlin 187.6 (Ndr. Frankfurt a.M. 1962); Le plus ancien manuscrit de la Notitia Dignitatum. Ed. par Henri Omont. In: Mémoires de la société nationale des antiquairès de France, série VI, Bd 1 (1890), S. 225-244; Notitia dignitatum imperii Romani. Réproduction réduit des 105 miniatures du manuscrit latin 9661 de la Bibliothèque Nationale. Ed. par Henri Omont, Paris 1911; CD-Rom-Edition: Concepción Neira Faleiro, La »Notitia Dignitatum «. Nueva edición crítica y comentario histórico, 2. ed., Madrid 2003 (= Departamento di Filologia, Universidad Complutense), hier S. 236-605; seit 2000 angekündigt: Notitia dignitatum. Hrsg. von Robert I. Ireland, Stuttgart. Die Abbildungen der Münchener Handschrift und einiger zeitgenössischer Parallelen enthält: Berger, The Insignia (wie Anm. 2), Abb. 1-134.

31 De rebus bellicis. Hrsg. von Robert I. Ireland, Leipzig 1984 (= Bibliotheca scriptorum Graecorum et Romanorum Teubneriana); Hartwin Brandt, Zeitkritik in der Spätantike. Untersuchungen zu den Reformvorschlägen des Anonymus von "De rebus bellicis", München 1988 (= Vestigia, 40). 

Dombibliothek Speyer abhing. Die Speyerer Abschrift entstand wahrscheinlich unter Karl dem Kahlen in den Jahren vor 846. Das Vorhandensein mehrerer zeitgenössischer Weltkarten (mappae mundi), von denen eine sogar als Tischplatte Karls des Großen diente, spricht für das gestiegene Bedürfnis nach Welterkundung in der karolingischen Epoche ${ }^{38}$. Nicht nur das unter Karl dem Großen zwischen Aachen und Konstantinopel erstmals auftretende Zwei-Kaiser-Problem, sondern auch das allmähliche Auseinanderfallen des west- und des ostfränkischen Reiches im 9. und 10. Jahrhundert könnten das am Hof bestehende Interesse am historischen Niedergang des Römischen Reiches verstärkt haben ${ }^{39}$. Die Überlieferungszeugen (sowie ein Druck) repräsentieren jedenfalls ein Ensemble aus etwa einem Dutzend verschiedener Texte, das geographischen Fragen, der Kriegführung sowie der Militär- und Zivilverwaltung gewidmet war ${ }^{40}$. Die Frage, ob diese Zusammenstellung auf der Interessenlage des karolingischen bzw. des ottonischen Hofes beruhte oder ob sie älteren Ursprungs war und dann nur um die Abhandlung des irischen Mönches Dicuil "Über das Ausmaß des Erdkreises" sowie das einem Fürstenspiegel ähnelnde »Gespräch des Kaisers Hadrian mit dem klugen Kind Epitus « erweitert worden ist ${ }^{41}$, lässt sich nur schwer abschließend beantworten. Im Falle der »Notitia dignitatum " geht die neueste Forschung für das Frühmittelalter von einer insularen und einer kontinentalen Handschriftengruppe aus. Ein Bindeglied zwischen beiden Überlieferungen wird in dem irischen Mönch Marianus Sco-

Robert Grigg, Ilustrations and Text in the Lost Codex Spirensis. In: Latomus, 46 (1987), S. 204-210; Concepción Neira Faleiro, El "Parisinus latinus 9661 « y la "Notitia Dignitatum«. Nuevas aportaciones. In: Latomus, 63 (2004), S. 425-453.

38 Zur Datierung: Faleiro, La Notitia dignitatum (wie Anm. 30), S. 84; zur Welterkundung der Karolinger: Van den Brincken, Mappa mundi (wie Anm. 24), S. 116; Alexander, The Illustrated Manuscripts (wie Anm. 2), S. 19 (Ndr., S. 80).

39 Ähnliche Überlegung: Faleiro, La Notitia dignitatum (wie Anm. 30), S. 42; zum Beginn der französischen bzw. der deutschen Geschichte im 11. Jahrhundert: Carlrichard Brühl, Deutschland - Frankreich. Die Geburt zweier Völker, 2. Aufl., Köln, Weimar, Wien 1995.

40 Ingo Maier, The Giessen, Parma and Piacenza codices of the »Notitia dignitatum«. In: Latomus, 27 (1968), S. 96-141; Ingo Maier, The Barberinus and Munich Codices of the "Notitia dignitatum«. In: Ebd., 28 (1969), S. 960-1035; nicht zugänglich war mir: Ingo Maier, Studies in the Textual Transmission of the "Notitia Dignitatum«, Diss. Melbourne 1975; dafür aber: Neira Faleiro, El "Parisimus latinus 9661 « (wie Anm. 37); vgl. auch Ingo Maier, Speyer Codex, http://members.ozemail.com.au/igmaier/webnot10.htm (Fassung vom 27.7.2005). Die spätantiken Quellen sind in folgenden Ausgaben greifbar: Corpus Iuris Romani Anteiustiniani. Hrsg. von Eduard Böcking, Bonn 1835; Geographi Latini Minores. Hrsg. von Alexander Riese, Heilbronn 1878; Chronica Minora Saeculorum IV. V. VI. VII. Hrsg. von Theodor Mommsen, Berlin 1892 (Ndr. München 1961) (= MGH AA, Bd 9/1); Notitia Dignitatum [verschiedene Ausgaben] (wie Anm. 30); Textes du droit Romain. Ed. par Paul Frédéric Girard, 5. ed., Paris 1923; Libellus de regionibus urbis Romae. Hrsg. von Arvast Nordh, Lund 1949 (= Skrifter utgivna av Svenska Institutet i Rom, series in octavo, 3); De rebus bellicis (wie Anm. 31).

41 Dicuil, Liber de mensura orbis terrae. Hrsg. von Gustav Parthey, Berlin 1870; Dicuil, Liber de mensura orbis terrae. Ed. by James J. Tierney with contributions by Ludwig Bieler, Dublin 1967 (= Scriptores Latini Hiberniae, 6); Das mittellateinische Gespräch Adrian und Epictitus nebst verwandten Texten (Joca monachorum). Hrsg. und unters. von Walter Suchier, Tübingen 1955; zu Letzterem als Fürstenspiegel: Pierre Riché, Ecoles et Enseignement dans le Haut Moyen Age. Fin du V' siècle - milieu du XI' siècle, Paris 1989, S. 288; außerdem: Virgilius Salisburgensis Aethici Istrici cosmographia Virgilio Salisburgensi rectius adscripta. Introd. by Terence Alan Martyn Bishop, Amsterdam 1966 (= Umbrae codicum occidentalium, 10). 
tus (1028-1086) gesehen, der nacheinander in Köln, Fulda und Mainz wirkte und daher den Aufbau der insularen Handschriftengruppe auf den Kontinent übermittelt haben könnte ${ }^{42}$.

Die »Epitome rei militaris« des Vegetius, eine unter dem letzten Gesamtkaiser Theodosius I. (379-395) oder auch erst unter dem weströmischen Caesar Valentinian III. (425-455) entstandene Reformschrift ${ }^{43}$, sind ebenfalls in einigen Fällen im Verbund mit anderen Texten erhalten geblieben. Sie wurden im Verlauf des 9. bis 11. Jahrhunderts sogar lateinisch wie volkssprachlich glossiert ${ }^{44}$. Ihre Lektüre erfolgte im gesamten Mittelalter vorrangig aus pädagogischem Interesse ${ }^{45}$. Schon die mit mindestens dreizehn Handschriften recht gut belegte karolingerzeitliche Rezeption ${ }^{46}$, die sich am Umgang der Bischöfe Frechulf von Lisieux ${ }^{47}$ und Hrabanus Maurus

42 Faleiro, La Notitia Dignitatum (wie Anm. 30), S. 47-114, 244 (gegenüber Ingo Maier erweitertes Stemma).

43 Spätdatierung: Michael Charles, Vegetius on Armour. The pedites nudati of the »Epitome rei militaris«. In: Ancient Society, 33 (2003), S. 127-167.

44 Veronika von Büren, Écrites au 9e, perdues au 20", retrouvées au 15e: à propos des gloses de Végèce »De rei militari $«$. In: Talking to the Text. Marginalia from Parpyri to Print. Proceedings of a Conference held at Erice, 26 September to 3 October 1998, as the $12^{\text {th }}$ Course of the International School for the Study of Written Records, vol. 1. Ed. by Vincenzo Fera, Giacomo Ferraù and Silvia Rizzo, Messina 2002 (= Percorsi dei classici, Reihe 4, 5), S. 269-288.

45 Frank Fürbeth, Zur deutschsprachigen Rezeption der »Epitome rei militaris« des Vegetius im Mittelalter. In: Die Wahrnehmung und Darstellung von Kriegen im Mittelalter und in der Frühen Neuzeit. Hrsg. von Horst Brunner, Wiesbaden 2000 (= Imagines medii aevi, 6), S. 141-165.

16 Max Manitius, Geschichte der lateinischen Literatur des Mittelalters. Erster Teil, München 1911 (= Handbuch der klassischen Altertums-Wissenschaft, 9/2/1), passim; Wilhelm Erben, Kriegsgeschichte des Mittelalters, München, Berlin 1929, S. 59 f.; Charles Reginald Shrader, The Ownership and Distribution of Manuscripts of Flavius Vegetius Renatus before the Year 1300, Ph.D. Columbia University 1976 (= University Microfilms International 76-28, 665), S. 17-35; Charles Reginald Shrader, A Handlist of Extant Manuscripts Containing the »De re militari« of Flavius Vegetius Renatus. In: Scriptorium, 33 (1979), S. 280-305, bes. S. 282, 286-305; Foster Halberg Sherwood, Studies in Medieval Uses of Vegetius' "Epitome rei militaris ", Los Angeles, CA 1980, S. 75-161; Charles Reginald Shrader, The influence of Vegetius' "De re militari«. In: Military affairs, 45 (1981), S. 167-172; Pieter F.J. Obbema, Een onbekend fragment van de "Notitia dignitatum ". Verslag van een expertise. In: De arte et libris. Festschrift Erasmus 1934-1984, Amsterdam 1984, S. 343-348 (zu dem Fragment Leiden, BPL 2869); Erich Somweber, Ein spätkarolingisches Fragment aus einem Werk des Vegetius. In: Jahrbuch des Vorarlberger Landesmuseumsvereins, 130 (1986), S. 59-76 (Fragment aus Buch III 4-6 aus einer Handschrift des 3. Viertels des 9. Jhs., wohl aus dem Kloster St. Gallen oder Reichenau, im dritten Viertel des 17. Jhs. im Kloster Einsiedeln als Einband benutzt); Von Büren, Écrites (wie Anm. 44), S. 281 (Sedulius als Benutzer von Vorlagen aus Lyon, Reims und St. Gallen, Notker Balbulus als Hersteller der einzigen Prachtausgabe von Vegetius, welche Karl dem Dicken zugedacht war), S. 284 (Wanderung des Vegetiustextes von Lyon nach Reims, wo die Kopie für Eberhard von Friaul angefertigt wurde, und nach St. Gallen, wo ihn Notker Balbulus verwandte).

47 Manitius, Geschichte (wie Anm. 46), S. 667 f.; Michael D. Reeve, Editorial opportunities and obligations, Rivista di filologia e di istr. In: Classica, 123 (1995), S. 479-499; Michael D. Reeve, Notes on Vegetius. In: Proceedings of the Cambridge Philological Society, n.s., 44 (1998), S. 182-218; Michael D. Reeve, The Transmission of Vegetius' "Epitoma rei militaris«, In: Aevum, 74 (2000), S. 243-354; Von Büren, Écrites (wie Anm. 44), S. 277 f. (Dresdener Handschrift Dedikationsexemplar Frechulfs von Liseux für Pippin von Aquitanien). 

. 

zeit möglicherweise sogar unter dem direkten Einfluss einer spätantiken Vorlage aus dem Westen des Römischen Reiches ${ }^{61}$.

Nicht nur die "Weltchronik" Frechulfs von Lisieux ${ }^{62}$, sondern auch die ehemalige Ausmalung der Königspfalz von Ingelheim ${ }^{63}$ belegen, dass der Aufstieg der Karolinger für die Zeitgenossen eng mit dem kriegerischen Wirken ihrer Vorgänger aus den untergegangenen Vier Weltreichen, insbesondere aber aus dem siegreichen Rom, verbunden war ${ }^{64}$. Der König selbst galt noch bis ins Zeitalter der Gregorianischen Reform hinein als Gesalbter des Herrn (Christus domini) und gehörte damit genauso zur Kirche wie zur Welt. Die Herrschervorstellung Karl des Großen lässt sich aber nicht nur vom alttestamentlichen Davidskönigtum, sondern auch vom römisch verstandenen Kaisertum her als kriegerisch erlangte Oberherrschaft über mehrere Völker und Reiche entschlüsseln ${ }^{65}$. Karolingische Herrscherbildnisse weisen vielleicht aus diesem Grunde neben anderen Motiven auch kriegerische Attribute auf ${ }^{66}$; und die spätrömischen Triumphzüge fanden nicht nur in Byzanz

61 Ernest Theodore De Wald, The Stuttgart Psalter. Biblia folio 23, Württembergische Landesbibliothek Stuttgart, Princeton, NJ 1930; Der Stuttgarter Bilderpsalter. Bibl. Fol. 23 Württembergische Landesbibliothek Stuttgart, 2 Bde, Stuttgart 1968; hier Bd 2, S. 151-222: Florentine Mütherich, Die Stellung der Bilder in der frühmittelalterlichen Psalterillustration, bes. S. 160-162, 200 f.; Vollständige Faksimileausgabe im Originalformat der Handschrift 32 aus dem Besitz der Bibliothek der Rijsuniversiteit te Utrecht. Komm. von Koert van der Horst und Jacobus Hendrik Anton Engelbregt, Graz 1984 (= Orbis artium, 8); Katharina Bierbauer, (Art.) Utrecht-Psalter. In: LMA, Bd 8, München, Zürich 1997, Sp. $1355 \mathrm{f}$.

62 Werner Goez, Zur Weltchronik des Bischofs Frechulf von Lisieux. In: Festgabe für Paul Kirn zum 70. Geburtstag dargebracht von Freunden und Schülern. Hrsg. von Ekkehard Kaufmann, Berlin 1961, S. 93-110; Nikolaus Staubach, „Christiana tempora«. Augustin und das Ende der alten Geschichte in der Weltchronik Frechulfs von Lisieux, FMASt, 29 (1995), S. 167-206.

63 Walther Lammers, Ein karolingisches Bildprogramm in der Aula regia von Ingelheim. In: Festschrift für Hermann Heimpel zum 70. Geburtstag am 19. September 1971, Bd 3. Hrsg. von den Mitarbeitern des Max-Planck-Instituts für Geschichte, Göttingen 1972 (= Veröffentlichungen des Max-Planck-Instituts für Geschichte, 36/3), S. 236-289, bes. S. 256-282 (Entwurf des weltlichen Teils des Bildprogramms auf der Grundlage von Orosius).

64 Thomas Scharff, Die Kämpfe der Herrscher und der Heiligen. Krieg und historische Erinnerung in der Karolingerzeit, Darmstadt 2002, weist diesen Grundtenor an Hand zahlreicher zeitgenössischer Quellen nach. Er folgt dabei einem religionswissenschaftlichen Ansatz und geht daher, wenn überhaupt, ohne ausdrückliche Benennung auf römische Komponenten ein; ebd., S. 134-146, 165-174.

65 Peter Classen, Romanum gubernans imperium. Zur Vorgeschichte der Kaisertitulatur Karls des Großen. In: Peter Classen, Ausgewählte Aufsätze. Hrsg. von Josef Fleckenstein, Sigmaringen 1983 (= VuF, 28), S. 187-204; Peter Classen, Karl der Große, das Papsttum und Byzanz, Sigmaringen 1985 (= Beiträge zur Geschichte des Mittelalters, 9); Henry Mayr-Harting, Charlemagne, the Saxons, and the Imperial Coronation of 800 . In: EHR, 111 (1996), S. 1113-1133.

66 Percy Ernst Schramm und Florentine Mütherich, Denkmale der deutschen Könige und Kaiser. Ein Beitrag zur Herrschergeschichte von Karl dem Großen bis Friedrich II. 768-1250, München 1962 (= Veröffentlichungen des Zentralinstituts für Kunstgeschichte in München, 2), S. 115, 121-123, 130 f., 134-137, Abb. 6, 22 f., 25, 43, 52, 56, 58 (Reiterstatuette Karls des Großen oder Karls des Kahlen); Harald Keller, Das Nachleben des antiken Bildnisses von der Karolingerzeit bis zur Gegenwart, Freiburg, Basel, Wien 1970, S. 49-62, bes. S. 57 f.; Wilhelm Köhler und Florentine Mütherich, Die Hofschule Kaiser Lothars, Berlin 1971 (= Florentine Mütherich, Die karolingischen Miniaturen, 5), S. 7-9, 52-59; Eggenberger, Psalterium (wie Anm. 60), Abb. 68, 190 f. 
und den frühmittelalterlichen Reichen, sondern auch bei den Karolingern Anklang ${ }^{67}$. Das "Paderborner Epos", das mit dem Empfang Papst Leos III. in Paderborn durch Karl den Großen und das fränkische Heer endet, vereint sogar Elemente der

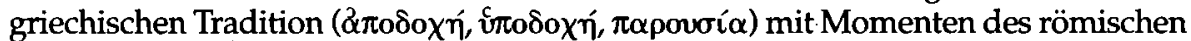
Zeremoniells (adventus, adoratio) und solchen der christlichen Liturgie (translatio, veneratio $)^{68}$. Heldenlieder, die am karolingischen $H$ of mündlich vorgetragen wurden, weisen hingegen neben römischen Elementen vor allem germanische Motive (zum Beispiel die Treue zum Freund im Vergleich zur Treue zum König) auf; diese werden aber häufig christlich (zum Beispiel in die Treue zwischen Mann und Frau) umgedeutet ${ }^{69}$.

Am Hof wurden im Laufe des Jahres auch die anstehenden Kriegszüge geplant. Ihre eigentliche Durchführung wurde auf der alljährlichen Reichsversammlung, die auf dem so genannten Maifeld stattfand, beschlossen ${ }^{70}$. Mehrwöchige bis mehrmonatige Feldzüge bildeten das Herzstück einer Strategie, die auf eine Ausdehnung des Karolingerreiches über seine bisherigen Grenzen angelegt war. Die Taktik Karls des Großen, die ihm später den Ruf eines »Sachsenschlächters" einbrachte, bestand in einem schnellen Einkreisen des Gegners mit Hilfe mehrerer kleiner Heere, die sich aus am Hof ausgebildeten Elitekämpfern zusammensetzten, in kurzen Überfällen, einer Politik der verbrannten Erde und systematischer Geiselnahme in den eroberten Landstrichen ${ }^{71}$. Dazu passt, dass man die "Epitome rei militaris" des

67 Michael McCormerick, Eternal Victory. Triumphal Rulership in Late Antiquity, Byzantium, and The Early Medieval West, Cambridge 1986.

68 Karolus Magnus et Leo papa. Hrsg. und übers. von Franz Brunhölzl. In: Karolus Magnus et Leo papa. Ein Paderborner Epos vom Jahre 799. Mit Beiträgen von Helmut Beumann, Franz Brunhölzl und Wilhelm Winkelmann. Hrsg. von Joseph Brockmann, Paderborn 1966 (= Studien und Quellen zur Westfälischen Geschichte, 8), S. 55/56-96/97, bes. S. 82/83-97/97; zur antiken und zur christlichen Tradition: Dagmar Stutzinger, Der Adventus des Kaisers und der Einzug Christi in Jerusalem. In: Spätantike und frühes Christentum. Ausstellung im Liebighaus, Museum alter Plastik, Frankfurt a.M., 16. Dezember 1983 bis 11. März 1984, Frankfurt a.M. 1983, S. 284-307; zum »Paderborner Epos" unter Betonung römischer Elemente: Achim Thomas Hack, Das Zeremoniell des Papstempfangs 799 in Paderborn. In: 799. Kunst und Kultur der Karolingerzeit. Karl der Große und Papst Leo III. in Paderborn. Katalog der Ausstellung Paderborn 1999, Bd 3. Hrsg. von Christoph Stiegemann und Matthias Wemhoff, Mainz 1999, S. 19-33.

69 Otto Zwierlein, Das Waltharius-Epos und seine lateinischen Vorbilder. In: Antike und Abendland, 16 (1970), S. 153-184; Alois Wolf, Mittelalterliche Heldensagen zwischen Vergil, Prudentius und raffinierter Klosterliteratur. Beobachtungen zum Waltharius. In: Sprachkunst, 7 (1976), S. 180-212; John O. Ward, The Function of the Epic in Latin Culture. The »Waltharius « and the Carolingian Attitudes Towards Marriage. In: The Epic in History. Ed. by Lola Sharon Davidson, Soumyendra Nath Mukherjee and Zdenko Zlatar, Sydney 1994, S. 66-111.

70 Hinkmar, De ordine palatii 6 (wie Anm. 51), S. 84/85-86/87; Matthias Springer, Jährliche Wiederkehr oder ganz anderes: Märzfeld oder Marsfeld? In: Rhythmus und Saisonalität. Kongreßakten des 5. Symposions des Mediävistenverbandes in Göttingen 1993. Hrsg. von Peter Dilg, Gundolf Keil und Dietz-Rüdiger Moser, Sigmaringen 1995, S. 297-324.

71 Jean François Verbruggen, L'armée et la stratégie de Charlemagne. In: Karl der Große. Lebenswerk und Nachleben, Bd 1. Hrsg. von Helmut Beumann, Düsseldorf 1967, S. 420-436; Helmut Beumann, Die Hagiographie »bewältigt«. Unterwerfung und Christianisierung der Sachsen durch Karl den Großen. In: Christanizzazione ed organizzazione ecclesiastica delle campagne nell'alto medioevo. Espansione e resistenze, vol. 1, Spoleto 1982 (= Settimene di studio del centro Italiano di studi sull'alto medioevo, 28/1), S. 129-163; Angelika Lampen, Sachsenkriege, sächsischer Widerstand und Kooperation. In: 799. Kunst und Kultur (wie Anm. 68), Bd 1, S. 264-272; zur Bewaffnung: Dieter 


$$
\text { . }
$$


Die Verarbeitung römischer Deutungsmuster des Krieges in frühchristlichen und germanischen Quellen

Die so genannte Konstantinische Wende hatte im Verlauf des 4. Jahrhunderts nicht nur zur Bejahung des Römischen Staates, sondern auch zur allmählichen Verschmelzung von Christianitas und Romanitas geführt. Eusebius von Cäsarea (um 260-um 340) integrierte als erster Theologe den Krieg in die christliche Ethik. Das Römische Weltreich besitzt bei ihm ganz im Sinne des Augustäischen Vorbilds die göttliche Aufgabe der Friedenssicherung. Der Kaiser sollte die sichtbaren Feinde des Glaubens bekämpfen, um dadurch die Ausbreitung des Evangeliums zu ermöglichen. Die Märtyrer erscheinen demgegenüber als Kämpfer für den Glauben. Während die Laien gerechte Kriege für die christliche Gesellschaft führen dürften, habe sich der Klerus ganz dem Gebet und damit Gott zu widmen ${ }^{79}$. Die Kirchenväter Johannes Chrysostomus (um 347-407), Hieronymus (um 347-um 420) und Kyrill von Alexandria (gest. 444) sahen in der Pax Romana sogar eine Erfüllung der Friedensprophezeiungen aus dem Neuen Testament ${ }^{30}$.

Ambrosius von Mailand (339-397) griff hingegen angesichts der drohenden Gotengefahr erstmals auf die Lehre Ciceros vom Gerechten Krieg zurück. So ist für ihn die Verteidigung des Römischen Reiches gegen die Barbaren genauso gerechtfertigt wie etwa der Schutz vor Dieben. Ambrosius setzte die Goten mit dem Volk Gog aus der Prophezeiung des Ezechiel gleich und deutete die Auseinandersetzung mit ihnen daher als eine Art von Gotteskrieg. Seiner Abhandlung "Über die Aufgaben der Kleriker« lag der Traktat »Über das rechte Handeln« zu Grunde. Die drei Bücher von »De officiis«, die der antike Redner Cicero als literarisches Vermächtnis an seinen Sohn gerichtet hatte, entstanden wahrscheinlich als kritische Reaktion auf die erfolgreichen Feldzüge und den politischen Aufstieg von Gaius Julius Caesar ${ }^{81}$. Sie enthalten ähnlich wie schon die "Reden gegen Verres ${ }^{82}$ eine auf stoischen Prämissen beruhende Interpretation der Tugenden. Die Tapferkeit erscheint dabei als Kardinaltugend, die für die Gerechtigkeit kämpft. Erst der gefahrvolle Einsatz für das allgemeine Wohl macht aus dem bloßen Wagemut rechte Tapferkeit. Die Gerechtigkeit hält dabei das natürliche Machtstreben, auf welchem die Tapferkeit beruht, in Schranken. Die fortitudo bestand für Cicero eigentlich aus zwei Komponenten: zum einen aus der Geringschätzung äußerer Werte, welche sich in der Beherrschung der Affekte und dem Ertragen von Schicksalsschlägen

79 Eusebius, Die Kirchengeschichte V 1-5, VI 1, 4-5, VII 5, VIII 1-17, IX 10-11, X 1-2, 3 Bde. Hrsg. von Eduard Schwartz und Theodor Mommsen. 2. Aufl. von Friedhelm Winkelmann, Berlin 1999 (= Die griechischen christlichen Schriftsteller der ersten Jahrhunderte, NF, $6 / 1-3)$, bes. Bd 1, S. 399/400-438/439, Bd 2, S. 518/519, 530/531-532/533, $538 / 539-542 / 543,736 / 737-794 / 795,838 / 839-852 / 853,856-860 / 861$, Bd 3, XVII-XLVII (älteste Handschriften aus dem 10. Jh.); Regis G. Gerest, Naissance de la théologie au service de l'église militante des $\mathrm{II}^{\mathrm{e}}$ et $\mathrm{III}^{\mathrm{e}}$ siècles. Notes de lecture d'Eusèbe de Césarée. Lumière et vie. In: Revue des formation doctrinale chrétienne, 14 (1965), S. 15-31. Zur christlichen Kriegsethik vgl. Anm. 5 f.

81 Hermann Strasburger, Ciceros philosophisches Spätwerk als Aufruf gegen die Herrschaft Caesars, Hildesheim, Zürich, New York 1990 (=Spudasmata, 45), S. 89-92.

82 Christian Rothe, Humanitas, fides und Verwandtes in der römischen Provinzialpolitik. Untersuchungen zur politischen Funktion römischer Verhaltensnormen bei Cicero, Berlin 1978 (= Schriften zur Geschichte und Kultur der Antike, 12), S. 13-19. 
äußert; zum anderen aus dem Vollbringen großer Taten angesichts von äußeren Gefahren. Der Vorrang politischer Leistungen vor dem reinen Macht- und Ruhmstreben des Feldherrn erweise sich schließlich daran, dass der gute Staatsmann der Vernunft folge. Ambrosius interpretierte dann zu Beginn des 5. Jahrhunderts seine antike Vorlage im Rahmen eines komplexen Adaptionsvorgangs (der so genannten Chrêsis) um. Die Tapferkeit des Christen, die sich im Kampf der Tugenden gegen die Laster erweist, erfährt dabei ihre größte Zuspitzung im Starkmut desjenigen, der Martyrium und Tod geduldig und sanftmütig auf sich nimmt, um den Glauben zu fördern. Diese christliche Neuinterpretation der fortitudo geschah nicht zuletzt durch zahlreiche Hinweise auf die militärischen Leistungen biblischer Gestalten aus den beiden Makkabäerbüchern. Ambrosius stellte ihnen allerdings ausdrücklich die Leidensannahme durch Hiob und das Martyrium des Laurentius gegenüber. Die jeweiligen exempla werden dabei einer Allegorese unterzogen, die im Sinne der Schule von Antiochia zwar den Eigenwert der historischen Beispiele beachtet, diese aber zugleich im Sinne der christlichen Botschaft anagogisch ausdeute ${ }^{83}$.

Die Eroberung der Stadt Rom durch Alarich im Jahre 410 war für den Geschichtsschreiber Orosius (380/385-nach 418) ${ }^{84}$ genauso wie für den Geschichtstheologen Augustinus (356-430) Anlass, um sich mit Krieg und Frieden in der menschlichen und in der göttlichen Geschichte zu befassen. Entscheidend für die christliche Kriegsethik wurde die Vorstellung vom Gerechten Krieg, die Augustinus in seiner Schrift "Gegen den Manichäer Faustus" entwickelte und mit seinem Lob des wahren Friedens in seinem historiographischen Hauptwerk »Vom Gottesstaat « vertieft hat. Er bediente sich dabei der römischen Kriegsvorstellungen, die er aber christlich uminterpretierte. Ziel allen menschlichen Handelns ist hiernach der von Gott geschenkte Frieden. Der göttliche Frieden bedeutet mehr als die Abwesenheit von Krieg und Gewalt, setzt aber den menschlichen Frieden voraus. Ein Krieg darf daher nur zur Wiederherstellung des Friedens, also zur Befreiung der Welt von der Sünde, geführt werden. Er ist damit gleichsam ein Akt der Nächstenliebe. Auch der Kämpfer selbst soll friedfertig sein, das heißt er ist grundsätzlich gehalten, stets das geringste Übel zu wählen und nur die der Situation angemessenen Mittel anzuwenden. Augustinus trennt also die innere Einstellung (recta intentio) des Kämpfers von der äußeren Tat. Die Übeltaten, die den Krieg begleiteten, erwüchsen oft aus unchristlichen Motiven wie Beutegier, Rache, Mordlust oder Ruhmsucht. Als gerechte Gründe (causae iustae), warum ein Krieg geführt werden darf, führt Augustinus nach römischem Muster die Verteidigung von Land, Gesetz und Sitten, die Bestrafung von Unrecht, die Wiedererlangung gestohlenen Eigentums und die ausstehende Vollstreckung eines Gerichtsurteils ins Feld. Die Wiederherstellung des göttlichen Rechts und der verlorenen Ordnung in einem zügellosen Gemein-

83 Maria Becker, Die Kardinaltugenden bei Cicero und Ambrosius: De officiis, Basel 1994 (=Chrêsis, 4), S. 115-160, bes. S. 151-157.

84 Paulus Orosius, Historiarum adversum paganos libri VII accedit eiusdem liber apologeticus. Hrsg, von Karl Zangemeister, Wien 1882 (Ndr. Hildesheim 1967), bes. S. VII-XXXIX (eine Handschrift des 6. Jhs. aus Lorsch, eine des 7. Jhs. aus Stablo, zwei Handschriften des 8. Jhs. aus Bobbio und Lorsch, neun weitere Handschriften des 8. und 9. Jhs.), XXIII-XXV (angelsächsische Übersetzung unter König Alfred, lateinische Übersetzung durch Hieronymus), XXVIII-XXXIII (Benutzung durch die »Descriptio orbis terrarum «, Cassiodor, Jordanus, Gregors von Tours, den Geographen von Ravenna, die Lorscher Annalen, Beda Venerabilis, Paulus Diaconus und Dicuil); Hans-Werner Goetz, (Art.) Orosius. In: LMA, Bd 6, München, Zürich 1993, Sp. 1474 f. 


$$
\text { . }
$$


: 
Enzyklopädie als Grundtext und den meist christlich geprägten Ergänzungen, die Hrabanus Maurus vor allem aus der Bibel schöpfte ${ }^{91}$, lässt sich auch an Hand seiner Erklärungen zum Krieg, den Kriegszeichen und den einzelnen Waffen nachvollziehen. So heißt es im Anschluss an Isidors Unterscheidung zwischen Kriegen, Schlachten und Kämpfen ganz im Sinne der augustinischen Tradition:

"So heißen nämlich diejenigen Kriege fleischlich, die von weltlicher Macht angezettelt werden.«

Im Übrigen gebe es aber bei den Christen und den gläubigen Dienern Gottes eine andere Art zu kämpfen. Es folgt eine längere, von mehreren Schriftzitaten eingeleitete Erklärung, wonach sich der Kampf der Christen gegen geistiges Unrecht wende oder im Streit mit den Lastern und dem Teufel bestehe. Der endgültige Frieden sei nur denen gegeben, die am jüngsten Tage heilig und von den Versuchungen des Fleisches unangetastet vor Gottes Angesicht träten. Erst im Anschluss an diese. Bemerkung nimmt Hrabanus Maurus den durch die »Etymologien « vorgegebenen Faden wieder auf, indem er auf die vier von Isidor genannten Auswirkungen eines Krieges sowie die Bedeutung der Wörter pax und foedus im Lateinischen eingeht ${ }^{92}$. Kaum größere Mühe hatte der Autor mit der christlichen Interpretation weltlicher Waffen. Auch in diesem Fall wurden etymologische Erklärungen beinahe nahtlos mit einer Allegorese der Heiligen Schrift verknüpft, die anders als im Falle des Ambrosius oder des Augustinus der Auslegungsmethode der Alexandriner folgte. So steht beispielsweise der Schild bei Hrabanus Maurus für den Glauben, und das Schwert wird für das Wort Gottes bzw. den göttlichen Urteilsspruch beim Jüngsten Gericht in Anspruch genommen. An die Stelle einer komplexen Um- und Weiterdeutung, wie sie insbesondere für die Patristik typisch war, trat somit bei Hrabanus Maurus ein einfaches Nebeneinander von christlichen und heidnischen Vorstellungsmustern ${ }^{93}$. Die Enzyklopädie des Fuldaer Abtes wurde wohl gerade wegen ihrer einfachen Denkschemata häufig benutzt. Die Tatsache, dass sie wahrscheinlich schon in der Karolingerzeit reich bebildert war ${ }^{94}$, dürfte ihrem Gebrauch zur Predigtvorbereitung und vielleicht auch für den Schulunterricht weiteren Vorschub geleistet haben.

Der Hinweis auf die Verwendung der Kirchenvätertexte führt noch einmal in die Spätantike zurück, da es nachfolgend vornehmlich um die Wahrnehmung der Römer als Kriegspartei und Militärmacht gehen soll. Einer der ältesten lateinischsprachigen Texte, die diese Frage aufgreifen, stammte von dem Bischof Hydatius von Aquae Flaviae (Chaves im heutigen Portugal). Seine annalistische Fortsetzung der "Weltchronik « des Hieronymus reicht von 379 (dem Jahr nach der nicht genannten Schlacht bei Adrianopel) bis 468/469 (einer Beschreibung der aktuellen

91 Elisabeth Heyse, Hrabanus Maurus Enzyklopädie »De rerum naturis«. Untersuchungen zu den Quellen und zur Methode der Kompilation, München 1969 (= Münchener Beiträge zur Mediävistik und Renaissance-Forschung, 4), S. 47-64. Hrabanus Maurus, De Universo XX 1 (wie Anm. 90), Sp. 531-534.

93 Ebd., XX 6. 12, Sp. 536-539, 542-543.

94 Paul Lehmann, Fuldaer Studien Neue Folge, Berlin 1927 (= SAB.PH, 2. Abhandlung), S. $13-47$, bes. S. 14 (Hinweis auf eine Ausgabe der Abbildungen einer Handschrift aus Montecassino von um 1023), 39 (Beschreibung von fünf Bildern zu Buch XX aus einer Handschrift für Ludwig III. von der Pfalz), 41-45 (eine nicht zu Ende illuminierte Vatikanhandschrift des 15 . Jhs. ermöglicht den Rückschluss auf einen spätkarolingischen bebilderten Codex von "De rerum naturis« aus Fulda). 
Kräfteverteilung zwischen Römern, Wisigoten und Sueben) ${ }^{95}$. Ihr zentrales Thema sind die bewaffneten Auseinandersetzungen zwischen den Kaisern und den germanischen Völkerschaften im (West-)Römischen Reich. Der Berichtshorizont des Chronisten umfasst dabei vor allem den westlichen Mittelmeerraum. Die römische Perspektive des Chronisten lässt sich am mehrfachen Gebrauch der Ausdrücke Beherrscher (dominantes) für die Römer, Barbaren (barbares) für die Gegner, Friedensbruch (pax rupta), ausplündern (depraedare), zum Beutemachen einfallen (invadere ad praedam) und Gemetzel (caedes) für die Handlungen der Gegner sowie schlagen (caedere) und Todeskampf (certamen) für die militärischen Begegnungen zwischen Römern und Germanen ablesen. Die Vorgehensweise der gegnerischen Völkerschaften wird meistens mit dem Verb "sich widersetzen« (rebellare) umschrieben. Die Germanen erscheinen jedoch andererseits auch als anerkannte Partner bei Waffenstillstandsverhandlungen (pax facta cum Romanis, in pace societas, aber auch pro pace mittuntur et obtinent conditiones iniunctas) oder sogar als Verbündete (foederati). Der Wisigote Theoderich II., der seinen Prinzipat auf Valentinian III. zurückführen könne, wird sogar als fidus Romano imperio bezeichnet. Beide hätten sich ja durch ein Friedensbündnis miteinander zu einem verbunden (quia uno essent pacis foedere copulati). So kann es auch nicht überraschen, dass Theoderich II. mit Willen und auf Anordnung des Kaisers Avitus einen Heerzug nach Spanien unternommen haben soll. Das Heerkaisertum des Avitus endet allerdings für den Chronisten mit seiner Tötung, weil dieser keine Anerkennung in Byzanz findet und die Goten ihm zudem die Hilfe entziehen. Die Ermordung seines Vorgängers Valentinian III. durch zwei Anhänger des Feldherrn Flavius Aëtius, dessen militärische Karriere der Chronist minutiös nachzeichnet, dessen Tod er aber auf himmlisches Einwirken (statt auf den Befehl des Kaiser) zurückführt, wird mit einem Hinweis auf die illegitime Erhebung seines kurzlebigen Nachfolgers Maximus durch den Senat verbunden. Der einige Jahrzehnte früher regierende Kaiser Magnus Maximus (388-393) erscheint sogar als Tyrann, weil er die Ausbreitung von Häresien wie dem Priscillianismus und damit die Zunahme der Gnosis ermöglicht habe. Der Chronist verfügte offenbar über gute Gewährsleute beim Heer, denn er widmet nicht nur der Laufbahn des Aëtius, sondern auch den Militärkarrieren weiterer Römer und den Kriegstaten des Wandalenkönigs Geiserich ausführliche Worte. Hydatius geht außerdem auf das Wirken bedeutender zeitgenössischer Bischöfe, auf Himmelserscheinungen, Naturereignisse und die Danielsprophetie ein. Die Übergriffe von Soldaten auf Kirchengut bildeten für ihn gleichsam die Nahtstelle zwischen den drei Themenkreisen Krieg, Kirche und Welt, zwangen sie ihn doch zu einer persönlichen Stellungnahme. Der Wandalenkönig Gunderich sei deshalb in Sevilla gefangen genommen worden, weil er frevelhaft mit seiner Hand nach der Kirche dieser Stadt gegriffen habe. Er sei bald darauf gestorben, da ihn ein Dämon auf Grund göttlichen Urteils befallen habe. Theoderich II. soll einige Jahre später die Plünderung der Stadt Braga ausgerechnet an einem Sonntag angeordnet haben. Die Römer wurden dabei gefangen, die Basiliken der Heiligen aufgebrochen, die Altäre abgeräumt und zerstört, die Jungfrauen Gottes abgeführt,

95 Die rein numerische Zählung der in der Chronik gemachten Jahresangaben nach Olympiaden bzw. Kaiserjahren ergibt einen Zeitraum von 379 bis 471 , der jüngste Eintrag erfolgte jedoch im dritten Regierungsjahr des letzten Kaisers, nach dem Hydatius zählt, also von Procop Anthemius (467-472), und damit im Jahre 469. 
$$
\text { . }
$$ 


\section{-}


und Goten münden dabei in einen Synkretismus eigener Prägung, heißt es doch in dem von Cassiodor diktierten Schreiben:

"Deshalb ist dieser Mann, der von den Kriegen in Bewegung gesetzt worden ist, an Glück hell, an Klugheit erprobt, sodass mit Gottes Weissagung gesagt wird, dass wir ihn zum Gipfel des gegenwärtigen Patriziats erheben. Begünstigt nun mit [euren] Weissagungen den Kandidaten und reserviert ihm bei unseren Männern die Hallen der Freiheit. Das Volk des Romulus ist zusammengekommen, die Männer des Mars als Kollegen zu erhalten ${ }^{103}$."

Einen ähnlichen Standpunkt spiegeln auch die "Drei Bücher römischer und gotischer Geschichte« des Jordanes, eines Zeitgenossen von Prokop und Cassiodor. Er kompilierte zunächst - vor allem auf der Basis der "Weltchroniken " des Eusebius und des Hieronymus sowie einer verlorenen alexandrinischen Chronik - eine zweiteilige »Römische Geschichte«, deren erster Teil mit Augustus und Christi Geburt abschließt und deren zweiter Teil mit Justinian endet. Sodann schrieb er die zwölf Bücher der ebenfalls verlorenen "Gotengeschichte" Cassiodors aus, um sie seinem Geschichtswerk als dritten Teil anzufügen. Dieser reicht bis kurz vor die Ankunft des oströmischen Heerführers Narses, der seit 552 im Auftrag Justinians siegreich gegen die Ostrogoten in Italien zu Felde zog. Ziel der Kompilation war es, die Herkunft und die Taten der Römer bzw. der Goten zu schildern. Hierzu zählten insbesondere auch militärische Verdienste ${ }^{104}$.

Während Cassiodor und Jordanes die Ostrogoten zu besseren Römern machen wollten, erscheinen die Wisigoten bei Isidor von Sevilla als ein Wandervolk, das auf die römischen Bewohner Südgalliens sowie der Iberischen Halbinsel trifft und dabei einen spezifischen Freiheitsmythos entwickelt ${ }^{105}$. Nicht nur das Gotenbild Isidors von Sevilla, sondern auch die Vorstellung Prospers von Aquitanien, dessen Fortsetzung der "Weltchronik « des Hieronymus die Kriege der Römer mit den so genannten Barbaren (Lombarden, Burgunder, Hunnen, Goten und Wandalen) anspricht ${ }^{106}$, und die Auffassung des Johannes von Biclaro, der eine weitere Ergänzung zu Hieronymus verfasst hat ${ }^{107}$, sind von dem religiösen Konflikt zwischen Arianern und Katholiken bestimmt. Johannes von Biclaro vergleicht König Rekkared, dessen Feldherr Claudius von Lusitanien mit Gottes Hilfe bei Carcassone eine Armee des fränkischen Königs Gunthram (561-593) geschlagen hatte, sogar mit den Kaisern Konstantin und Marcian, die den Konzilien von Nicäa und Chalzedon vorangestanden hätten ${ }^{108}$. Seine annalistischen Notizen geben zahlreiche Hinweise auf mili-

Magnus Aurelius Cassiodorus Senator, Variae VIII 10 (wie Anm. 101), S. 239-241; MeyerFlügel, Das Bild (wie Anm. 18), S. 62, 82.

104 Iordanes, Romana et Getica. Hrsg. von Theodor Mommsen, Berlin 1882 (Ndr. München 1982; = MGH AA, 5/1); Walter Goffart, The Narrators of Barbarian History (A.D. 550-800). Jordanes, Gregory of Tours, Bede, and Peter the Deacon, Princeton, NJ 1988, S. 20-111.

105 Wolfram Drews, Goten und Römer als Gegenstand der Historiographie bei Isidor von Sevilla. In: Saeculum, 53 (2002), S. 1-20.

106 Conquerors and Chroniclers of Early Medieval Spain. Trans. with notes and introd. by Kenneth Baxter Wolf, 2. ed., Liverpool 1999, S. 3-5.

107 Johannes de Biclaro, Chronica. Hrsg. von Theodor Mommsen, Hannover 1894 (Ndr. Berlin 1961; = MGH AA, 11), S. 207-220; Juan de Biclaro, obispo de Gerona, su vida y su obra. Intro., texto crit. y com. por Julio Campos, Madrid 1960; Teillet, Des Goths (wie Anm. 96), S. 428-455; Conquerors (wie Anm. 106), S. 1-10, 57-77.

108 Johannes de Biclaro, Chronica 91 f. (wie Anm. 107), S. 218-220; Conquerors (wie Anm. 106), S. 7-10 (Hinweis auf Konstantin). 
tärische Vorkommnisse im Byzantinischen Reich. Aufgeführt werden Schlachten, Eroberungen und Friedensschlüsse, mehrere Stadtbelagerungen sowie die Namen und Titel von römischen Militärbeamten aus dem Mittelmeerraum. Für das Jahr 575 wird der Triumphzug des Tiberius in Byzanz nach einem Sieg über die Perser hervorgehoben. Im Sinne der Vorstellung von Rekkared als neuem Konstantin werden die kriegerischen, kirchlichen und politischen Erfolge der gotischen Könige im Westen jeweils im Anschluss an die militärischen und politischen Taten der Byzantiner im Osten geschildert. Dazu zählt etwa die Gründung der Städte Recopolis (benannt nach Rekkared, bei Zorita de los Canes in der Guadaljara gelegen) und Victoriacum (wahrscheinlich das heutige Vittoria, benannt nach dem Siegesreichtum Leovigilds). Die Belagerung und die Einnahme der Stadt Sevilla sollen im Jahre 583 mit Hilfe von Hunger, dem Schwert und einem künstlichen Aufstauen des Flusses Guadalquivir vonstatten gegangen sein. Vom Einsatz von Belagerungsmaschinen ist hingegen keine Rede ${ }^{109}$.

Auch Isidor greift vor allem auf die bewaffneten Auseinandersetzungen mit den Römern zurück, um die These zu belegen, dass die Friedensherrschaft des wahren Glaubens, die nach der Konversion des Königs Rekkared zum Katholizismus eingetreten sei, den Ruhm des Schwertes, mit dem die Wisigoten ihre Herrschaft errungen hatten, gleichsam voraussetzt. Während die in der "Gotengeschichte "Isidors genannte Devise, wonach jedes in sich geteilte Reich der Zerstörung anheimfällt, biblischen Ursprungs ist (Lukas 11, 17), ist die metaphorische Kennzeichnung Spaniens als einer Braut, die nicht (mehr) von Rom verlangt und auch nicht von Romulus besessen wird, sondern vielmehr von den Goten geliebt ist, antiker Herkunft. Isidor kannte zudem noch einige militärische Riten der Römer. Er nennt zum einen den Brauch, eine goldene Statue und ein goldenes Medaillon mit dem Porträt eines Schlachtensiegers im römischen Kapitol aufzustellen, für Claudius Augustus (268-270), zum anderen den öffentlichen Lobpreis der Römer für Konstantin I. nach seinem Sieg über die Goten von 332. Dem Feldherrn Litorius, der unter Kaiser Valentinian III. (425-454) diente, brachte die Beachtung der römischen Tradition allerdings wenig Glück. Als er nämlich vor einem Gotenfeldzug Wahrsager nach dem Erfolg seiner Unternehmung befragte, wurde er von Dämonen heimgesucht, was ihm schließlich den Tod in der Schlacht einbrachte. Auch die Stellung des Goten Theoderich, den der römische Senat ebenfalls mit einer goldenen Statue geehrt haben soll, als Föderatenkönig in Italien findet Erwähnung. Die Einnahme der Stadt Rom durch Alarich im Jahre 410 wird schließlich als deditio beschrieben. Alle Bewohner, die an den heiligen Orten Zuflucht gesucht hätten, sollen nämlich von der Gefangennahme oder Tötung und alle sakralen Gegenstände von der Plünderung ausgenommen worden sein. Auch Friedensverträge (pacta) als Mittel, einen Krieg zu beenden, führt Isidor mehrmals auf. Von militärtechnischen Einzelheiten wie etwa der täglichen Wehrertüchtigung gotischer Männer ist hingegen nur ausnahmsweise die Rede. Die Seefahrt und die Belagerungstechnik der Goten sollen sogar erst im 6. Jahrhundert soweit gediehen sein, 
,

$-$ 

nicht vertieft behandelt hat, eingegangen ${ }^{124}$. Gregor von Tours stützte sich vor allem auf die "Vulgata", die Weltchroniken des Eusebius und Hieronymus, die "Sieben Bücher gegen die Heiden « des Orosius sowie einige Heiligenleben, um die vergangenheitsgeschichtlichen Teile seiner Chronik zusammenzustellen. Daneben kamen auch zwei verlorene Geschichtswerke zum Tragen: Gregor entnahm nämlich der »Historia " des Sulpicius Alexander zwei Nachrichten über die Franken zwischen 388 und 393 und der Geschichtsdarstellung des Renatus Profuturus Frigiredus eine Stelle über die Franken im Jahre $406^{125}$. Die Einstellung der beiden spätrömischen Verfasser zu den Ereignissen lässt sich trotz der Tatsache, dass Gregor die Übernahmen unter die Frage nach der politischen Verfassung der frühen Franken gestellt hat, in ihren Grundzügen rekonstruieren. Sulpicius Alexander gehörte vermutlich ins Umfeld der magistri militarium Nanninus, Carietto und Syrus, deren Truppen gegen Ende des 4. Jahrhunderts in Mainz stationiert waren und dabei den militärischen Aufstieg des Frankoromanen Arbogast miterlebten. Möglicherweise handelte es sich bei ihnen sogar um Anhänger des Kaisers Theodosius II., dem später die Niederwerfung des Arbogast zuzuschreiben war. Die Kaiser Maximus, Valentinian II. und Eugenius werden demgegenüber wegen ihrer militärischen und moralischen Schwächen von Sulpicius Alexander als Tyrannen charakterisiert. Die Soldaten hätten selbst den persönlichen Befehlen Valentinians trotz ihres Eides gegenüber dem Kaiser nicht mehr gehorcht. Nachdem ein römischer Feldzug nach Germanien aus Mangel an einem eigenen Lager, durch vorschnelle Verwüstung der Häuser des Gegners und an einem Hinterhalt, in den die Franken die Römer gelockt hatten, gescheitert war, soll es stattdessen allein Arbogast geglückt sein,

seiner Fortsetzungen sowie dem aus neustrischer Perspektive verfassten "Liber historiae Francorum « zwar eine Unterscheidung zwischen Franken und Romanen; sie habe sich aber im Laufe des 6. und 7. Jahrhunderts mehr und mehr zu Gunsten eines politisch konnotierten Frankenbegriffs abgeschwächt.

124 Richard Salomon, Belisariana in der Geschichtsschreibung des abendländischen Mittelalters. In: BZ, 30 (1929/30), S. 102-110, bes. S. 103; Michel Banniard, L'aménagement de l'histoire chez Grégoire de Tours. A propos de l'invasion de 451. In: Romanobarbarica, 3 (1979), S. 5-38; Jonathan Barlow, Gregory of Tours and the Myth of the Trojan Origins of the Franks. In: FMASt, 29 (1995), S. 86-95; Gregor Neumann, Das Chlodwigbild bei Gregor von Tours. In: Chlodwig und die "Schlacht bei Zülpich". Geschichte und Mythos 496-1996. Begleitbuch zur Ausstellung in Zülpich, 30.8.-26.10.1996. Hrsg. von Dieter Geuenich, Euskirchen 1996 (= Geschichte im Kreis Euskirchen, 10), S. 81-86; Ralph Witney Mathisen, Clovis, Anastase et Grégoire de Tours. Consul, patrice et roi. In: Clovis (wie Anm. 5), S. 395-407; Philip Wynn, Wars and Warriors in Gregory of Tours' Histories I-IV. In: Francia, 28/1 (2001), S. 1-35; Bernard S. Bachrach, Gregory of Tours as a Military Historian. In: The World of Gregory of Tours. Ed. by Kathleen Anne Mitchell and Ian N. Wood, Leiden 2002 (= Cultures, Beliefs and Traditions, 8), S. 351-363; Walter Goffart, Conspicuously absent. Martial Heroism in the »Histories « of Gregory of Tours and Its Likes, ebd., S. 365-393; Miriam Czock, »Wo gesündigt wird, kann der Sieg nicht gewonnen werden «. Plünderung von Kirchen im Krieg in den Werken Gregors von Tours (538-594). In: Blicke auf das Mittelalter. Aspekte von Lebenswelt, Herrschaft, Religion und Rezeption. Festschrift für Hanna Vollrath zum 65. Geburtstag. Hrsg. von Bodo Gundelach und Ralf Molkenthin, Herne 2004 (= Studien zur Geschichte des Mittelalters, 2), S. 13-23; zu Fredegar weiter unten.

125 Gregor von Tours, Zehn Bücher Geschichten, Bd 1. Hrsg. und übers. von Rudolf Buchner. Mit einem Nachtrag von Steffen Patzold im zweiten Band, 8. Aufl., Darmstadt 2000, S. XXV-XXX, bes. S. XXV-XXVI. 
die ehemaligen Stammesgenossen durch Brandschatzung bei einem Winterfeldzug zu überwinden ${ }^{126}$.

Renatus Frigiredus wird durch Gregor von Tours vor allem in Hinsicht auf die Militärlaufbahn des Aëtius zitiert. Der Chronist scheint dabei ähnliche Ansichten zu den spätrömischen Kaisern und Militärbefehlshabern vertreten zu haben wie der bereits erwähnte Bischof Hydatius. Der Vater des Aëtius kam aus Scythien und war dann im Heeresdienst bis zum magister equitum der Prätorianer aufgestiegen. Die Mutter stammte aus Italien. Bereits als Kind in die Prätorianergarde aufgenommen, wurde Aëtius nacheinander als Geisel zu den Goten und den Hunnen geschickt, wobei er Letzteren zeitlebens verbunden blieb. Er vollzog dann einen raschen Aufstieg im römischen Heer, der ihn schließlich zum Aufseher im Palast des weströmischen Kaisers machte. Seine Persönlichkeit entsprach in jederlei Hinsicht den römischen Idealvorstellungen von einem Soldaten, war er doch medii corporis, virilis habitudinis, decedenter formatus, quo neque infirmitudine esset neque oneri, animo alacer, membris vegitus, eques prumptissimus, sagittarum iactu peritus, contu inpiger, bellis aptissimus, pacis artibus celebris, nullius avaritiae, minime cupitidatis, bonis animi praeditus, ne inpulsoribus quidem pravis ab instituto suo devians, iniuriarum patientissimus, laboris adpretens, inpavidus periculorum, famis, sitis, vigiliarum tolerantissimus. Aëtius fiel jedoch einem Mordanschlag Valentinians II. zum Opfer, der fürchtete, dieser wolle ihn vom Thron stürzen. Wenige Jahre später wurde der tyrannische Kaiser daher selbst von zwei Anhängern des Ermordeten mit dem Schwert durchbohrt, als er vom Marsfeld zu seinem Volk redete ${ }^{127}$.

Das Bild, das Gregor von Tours von den byzantinischen Imperatoren der eigenen Zeit entwirft, fällt differenzierter aus als das Kaiserbild bei seinen beiden spätantiken Gewährsleuten. Den Hauptanlass, um über die Imperatoren zu sprechen, bildet das unglückselige Schicksal der Schwester König Childeberts II., Ingunde. Als Gemahlin des zum Katholizismus übergetretenen Wisigoten Hermenegild stand sie im Zentrum der kriegerischen Auseinandersetzungen zwischen dem arianischen König der Wisigoten, Leuvigild, den Byzantinern und den Franken. Ihr Tod als byzantinische Geisel in Afrika führte auch innerhalb der Merowingersippe zu heftigen Konflikten ${ }^{128}$. Die Kriegführung und die diplomatischen Verhandlungen zwischen den drei beteiligten Parteien lassen sowohl die Wahrung des kirchlichen Asyls als auch die Durchführung der römischen deditio als Handlungsnormen erkennen ${ }^{129}$. Der byzantinische Kaiser Tiberius wird dabei im Gegensatz zu seinem Vorgänger Justin II. nicht nur als kriegstüchtig, sondern auch als gütig und weise charakterisiert $^{130}$. Eine seiner Münzen, die Gregor von Tours bei einer Reise persönlich zu Gesicht bekam, zeigte den Kaiser mit Namen und Titel auf der Vorder-

126 Ebd., II 9, S. 80/81-86/87.

127 Ebd., II 8, S. 80/81; zum Ideal eines römischen Feldherrn: J. Brian Campbell, Teach Yourself How to Be a General. In: JRS, 77 (1987), S. 13-29; Bachrach, Gregory (wie Anm. 124), S. 352 f.; zu Aëtius als Feldherrn: Tino Stickler, Aëtius. Gestaltungsspielräume eines Heermeisters im ausgehenden Weströmischen Reich, München 2002 (=Vestigia, 54); zu Geiseln: Gabriele von Olberg, (Art.) Geisel. In: Johannes Hoops. Reallexikon der Germanischen Altertumskunde. Hrsg. von Heinrich Beck [u.a.], Bd 10, Berlin, New York 1998, S. 572-576.

128 Belege: Gregor von Tours, Zehn Bücher Geschichte (wie Anm. 125), Bd 2, S. 443 (s.n. Ingundis, T. Sigiberts I.).

129 Ebd., V 38, S. 350/351-352/353; ebd., VII 36-39, Bd 2, S. 138/139-148/149.

130 Ebd., V 30, S. 336/337-338/339. 
,

. 

liche Kriegsdeutung ausgewertet worden ist ${ }^{142}$. Unterzieht man die »Historia« einer Befragung auf römische Kriegführung und auf römische Kriegsdeutungen hin, so erweisen sich der unter Einbeziehung der geostrategischen Gegebenheiten geplante Feldzug mit drei Heeressäulen, von denen eine zur See agiert und eine weitere in kleinere mobile Verbände aufgespalten wird ${ }^{143}$, das Aufschlagen eines festen Lagers $^{144}$, die Benutzung von akustischen Signalen und Standarten für den Angriff ${ }^{145}$, die Anwendung von Feuer und Belagerungsmaschinen zur Eroberung einer Stadt ${ }^{146}$, die Hoffnung auf Schutz im städtischen Amphitheater ${ }^{147}$, die deditio eroberter Städte ${ }^{148}$, das Ablegen der königlichen Kleider ${ }^{149}$, der Triumphzug des siegreichen Königs und die gleichzeitige Schandprozession der Kriegsgefangenen ${ }^{150}$, die Betonung der Wehrtauglichkeit des gotischen Volkes ${ }^{151}$ sowie die Bewertung des Krieges als unvermeidbares Mittel königlicher Machtpolitik ${ }^{152}$ als wichtigste Momente. Diese wurden wahrscheinlich von den Byzantinern nach Spanien vermittelt. Ihnen stehen die Hinweise auf die gotische Sitte, dass der König mit seinen Füßen über das Rückgrat des unterworfenen Gegners schreitet und dieser anschließend skalpiert oder zumindest tonsuriert wird ${ }^{153}$, sowie als christliche Leitbilder das Asyl in der Bischofskirche ${ }^{154}$, die Verwerfung der Rache und die innere Reinigung als Voraussetzungen für den guten Kampf ${ }^{155}$ sowie die angebotene Verzeihung für den Frevel des Besiegten ${ }^{156}$ gegenüber. Dazu passt, dass Julian für die Stilisierung seiner Kriegsmonographie nicht nur die Schriften von Livius, Sallust und Vergil verwendet, sondern auch die "Geschichtsbücher gegen die Heiden « von Orosius, die zeitnahen "Akten der Konzilien von Toledo" und die zeitgenössischen $»$ Gesetze der Wisigoten « benutzt hat ${ }^{157}$.

142 Bronisch, Reconquista (wie Anm. 6), S. 57-61, 327-347; Mayke de Jong, Adding insult to injury. Julian of Toledo and his »Historia Wambae«. In: The Visigoths from the Migration Period to the Seventh Century. An Ethnographic Perspective. Ed. by Peter Heather, San Marino 2003, S. 373-402.

143 Historia Wambae regis 10 f. 13 (wie Anm. 141), S. 510-512, 513.

144 Ebd., 11, 27, S. 511, 523.

145 Ebd., 13. 16, S. 514, 515 f.; zu Standarten im römischen Heer: Helgeland, Roman Army Religion (wie Anm. 10), S. 1473-1478; zu byzantinischen Standarten: Rolf Grosse, Die Fahnen in der römisch-byzantinischen Armee. In: BZ, 26 (1924), S. 359-372.

146 Historia Wambae regis 18 (wie Anm. 141), S. 516.

147 Ebd., 12, S. 512 f.; zum Stellenwert der Außenmauern einer römischen Stadt oder eines römischen Lagers: Helgeland, Roman Army Religion (wie Anm. 10), S. 1488-1495.

148 Historia Wambae regis 12. 18-30 (wie Anm. 141), S. 512 f., bes. S. 512 (Ablehnung der deditio von Narbonne), 516-526 (teilweises Scheitern der deditio von Nîmes führt zur Plünderung der Stadt, zur Vernichtung eines Großteils der Stadtbevölkerung, zur Ausstellung der angeketteten Kriegsgefangenen und zum Triumphzug des siegreichen Königs, aber auch zur Freilassung der Kriegsgefangenen, die zu den Verbündeten des Feindes gehören, zur Neuordnung der unterworfenen Provinz und zum Wiederaufbau der eroberten Stadt).

149 Historia Wambae regis 21 (wie Anm. 141), S. 518; zum Ablegen der römischen Kriegstoga: Helgeland, Roman Army Religion (wie Anm. 10), S. 1495.

150 Historia Wambae regis 9.30 (wie Anm. 141), S. 508, $525 \mathrm{f}$.

151 Ebd., 16, S. 515; vgl. hierzu den Abschnitt zu Cassiodor weiter oben.

152 Historia Wambae regis 9 (wie Anm. 141), S. $507 \mathrm{f}$.

153 Ebd., 27, S. 522; zum morbus goticus Anm. 136.

154 Ebd., 18, S. 516.

155 Ebd., 10, S. 509 f.

156 Ebd., 21 f., S. 518 f.

157 Ebd., passim; Manitius, Geschichte (wie Anm. 46), S. 131; zu Kriegsmonographien Anm. 97. 
Die etwa zwei Generationen jüngere "Kirchengeschichte des englischen Volkes" des Beda Venerabilis beruht hingegen außer auf Plinius dem Älteren, Prosper von Aquitanien, Orosius und einigen hagiographischen Quellen vor allem auf Gildas. Beda suchte die Romanitas vor allem in der Symbiose der römischen Kirche mit dem Volk der Angeln, Sachsen und Jüten ${ }^{158}$. Ein Vergleich der wenigen Schlachtenbeschreibungen, die Beda gibt, erweist, dass er sich kaum für militärgeschichtliche Einzelheiten interessierte ${ }^{159}$, sondern vielmehr exemplarische Geschichten für die geläufigen Vorstellungen vom Gerechten $\mathrm{Krieg}^{160}$, vom Heiligen Krieg ${ }^{161}$ und vom Schlachtenheil ${ }^{162}$ formulierte. Während ihm der Raub von Kirchengut ebenso wie seinen Vorgängern ein Dorn im Auge war ${ }^{163}$, fand der Kriegsdienst von Bischöfen unter Umständen sogar seine Zustimmung ${ }^{164}$. Die Strategie des Bischofs Germanus, sich der an Zahl und Erfahrung weit überlegenen Feinde zu erwehren, bestand beispielsweise in rechtzeitiger Ausspähung, der Hebung der Truppenmoral durch Predigten und Taufen sowie der Anwendung einer Kriegslist ${ }^{165}$. Weitere Elemente der zeitgenössischen Kriegführung lagen im Ausnutzen landschaftlicher Vorteile ${ }^{166}$ und in der Scheinflucht ${ }^{167}$. Der Hadrianswall und die Errichtung zusätzlicher Wachttürme an der Küste werden mit der Abwehr der Picten und Scoten durch die Römer in Verbindung gebrach $t^{168}$. Römisch ist neben dem Hinweis auf die Notwendigkeit, einen Wall zu befestigen ${ }^{169}$, auch die Stilisierung Caesars zu einem erfahrenen Feldherrn und Strategen, der allerdings in Britannien letztlich gescheitert sei ${ }^{170}$.

Paulus Diaconus, der letzte der hier behandelten Autoren, stammte aus einer vornehmen langobardischen Familie, kam im Laufe seines Lebens mit dem beneventanischen Hof sowie mit Karl dem Großen in Kontakt und starb als Mönch im Kloster Montecassino. Seine historiographische Tätigkeit erstreckte sich nicht nur auf die nach dem Vorbild des "Liber Pontificalis " geschilderten "Taten der Bischöfe von Metz «, eine Lebensbeschreibung Papst Gregors des Großen und eine »Römische Geschichte«, welche das Geschichtswerk des spätantiken Schriftstellers Eutropius bis zur Eroberung Italiens unter Justinian fortsetzte, sondern auch auf die »Historia Langobardorum«. Sie vereint nicht nur Züge einer origo gentis mit genealogischen

158 Goffart, The Narrators (wie Anm. 104), S. 235-328.

159 Bede's Ecclesiastical History of the English People I 20. Ed. by Bertram Colgrave and Roger Aubrey Baskerville Mynors, Oxford 1969 (= Oxford Medieval Texts), S. 62/63-64/65 (unter Kaschierung einer mutmaßlichen Plünderung).

160 Ebd., III 2. 24, S. 214/215, 218/219, 288/289-294/295 (wohl eine Abwägung des göttlichen Friedens gegenüber dem menschlichen Waffenstillstand).

161 Ebd., I 20. III 14, S. 62/63-64/65, 254/255-260/261, bes. S. 256/257.

162 Ebd., III 18, S. 266/267-268/269 (Konfrontation des Schlachtenheils des Königs mit der Demut des Mönchs).

163 Ebd., IV 26 (24), S. 426/427-430/431.

164 Ebd., I 20. II 2, S. 62/63-64/65, 134/135-142/143 (Bischöfe von Caerlon verlieren die Stadt an Aelfrith, weil sie das Osterfest zum falschen Termin, also »unrömisch «, gefeiert haben).

165 Ebd., I 20, S. 62/63-64/65.

166 Ebd., III 24, S. 288/289-294/295, bes. S. $290 / 291$.

167 Ebd., IV 26 (24), S. 426/427-430/431, bes. S. 428/429.

168 Ebd., I 12, S. 40/41-44/45, bes. S. 44/45.

169 Ebd., I 5, S. 24/25-26/27; zur Vegetiusbenutzung: Charles H. Jones, Bede and Vegetius. In: Classical Review, 46 (1932), S. 248 f.

170 Bede's Ecclesiastical History I 2 (wie Anm. 159), S. 20/21-22/23, nach: Orosius, Historiarum adversum paganos VI 7-10 (wie Anm. 84), S. 369-382. 
Elementen, die als Hausüberlieferung der langobardischen stirps regia anzusprechen sind, sondern weist gleichzeitig Merkmale einer Kirchen- und Reichsgeschichte auf ${ }^{171}$. Obwohl Paulus Diaconus für die römischen Teile seines Hauptwerks neben einer zwischen 672 und 688 entstandenen $»$ Herkunftsgeschichte ${ }^{172}$ und den »Volksrechten« der Langobarden vor allem christliche Quellen wie etwa die »Zehn Bücher Geschichte" Gregors von Tours, das Briefregister Gregors des Großen, den »Liber Pontificalis«, die "Chronik« und die "Kirchengeschichte« Bedas herangezogen hat, besitzen viele seiner Nachrichten zu den Byzantinern keine feststellbaren Parallelen. Da es zudem mehr als hundert Handschriften der "Langobardengeschichte" gibt, von denen mindestens sechzehn im Karolingerreich oder seinen Nachfolgestaaten und eine weitere in England erhalten blieben, verdienen die dort getroffenen Aussagen zur Kriegführung der Römer und der Byzantiner besonderes Interesse ${ }^{173}$.

Der Chronist beschreibt die Ereignisse und Personen mit Hilfe einfacher Freundund Feindbilder, die er häufig mit einer moralischen Schwarz-Weiß-Bewertung versieht. Christlich geprägte Deutungsmuster des Krieges treten dabei fast völlig in den Hintergrund ${ }^{174}$. Die christlichen Deutungsmuster des Krieges weisen zudem

171 Goffart, The Narrators (wie Anm. 104), S. 329-431.

172 Origo gentis Langobardorum. Hrsg. von Georg Waitz, Hannover 1878 (Ndr. Hannover 1988; = MGH SS rer. Langobard), S. 1-6; mir nicht zugänglich waren: Origo gentis Langobardorum. A cura di Caudio Azzara e Stefano Gasparri. In: Azzara/Gasparri, Le leggi dei Longobardi. Storia, memoria e diritto di un popolo germanico, Milano 1992, S. 2-7; Origo gentis Langobardorum. A cura di Annalisa Bracciotti, Roma 1998 (= Biblioteca di Cultura Romanobarbarica, 2), S. 105-119.

173 Paulus [Diaconus], Historia Langobardorum. Hrsg. von Georg Waitz, Hannover 1878 (Ndr. Hannover 1987; = MGH SRG in us. schol., 48), S. 23-44.

174 Ebd., I 12. 16. 17. 20. 21. 23. 24.27 f. 31 f. 34 . IV 2. 4.12 f. 15 f. 20.23 f. 28. 30.36 f. 40.42. 46. V I f. 4-7. 9. 16. 19-21. 23. 28 f. 32. 36. 38. 40 f. VI 17. 19 f. 22. 24. 27. $3545-47.55$, S. 60 (Zweikampf eines Sklaven statt Entscheidung durch eine Schlacht), $62 \mathrm{f}$. (Entführung der Königstochter), 63 (Schlachtrede, die die Freiheit als höchstes Gut betont), 65-68 (Verrat führt zur Notwendigkeit, nackt in die Schlacht zu ziehen, die Folgen der Rache), 70 f. (Zweikampf, Flucht und Beute als Schlachtelemente, Kriegslist), 79-81 (Haupt des Gegners als Trinkgefäß), $104 \mathrm{f}$. (Tod eines Königs wegen Verrats durch eine Frau und wegen gottlosen Verhaltens), 136-138 (Epidemie im Frankenheer, Auslösung von Kriegsgefangenen durch zwei Bischöfe, Säule als Grenzzeichen), 139 (Vision), $140 \mathrm{f}$. (ewiger Frieden der Langobarden mit den Franken, Kennzeichnung des Langobardenherzogs Agilulf als strenuus et bellicosus et tam forma quam animo ad regni gubernacula coaptatus), 144 (Rückführung von Kriegsgefangenen), $145 \mathrm{f}$. (Frieden mit den Awaren und Entscheidungsschlacht zwischen zwei Merowingern mit 30000 Gefallenen), 150 (zwei Friedensschlüsse), 151-153 (meteorologische Vorzeichen und Schlachtenwunder durch den heiligen Savinus), 154 f. (prominente Geiselnahme durch die Byzantiner), 156 f. (Schleifung der Stadt Padua, Frieden mit Entlassung feindlicher Soldaten), 157 (Geiselnahme der Byzantiner als Kriegsgrund), 160-164 (Bürgerkriege in Ägypten und Angriffskrieg der Perser von außen unter Kaiser Phokas, gescheiterte Ubergabeverhandlungen in Friaul führen zur Tötung der Erwachsenen und Versklavung der Frauen und Kinder durch die Awaren, Vergewaltigung und Ermordung der Herzogin Romilda durch den Awarenkönig und seine Männer als gerechtes Ende für eine lüsterne Verräterin), 168-170 (Waffenstillstände, Verstandesverlust des Königssohnes Arodus wegen Arianismus), 171 (Stilisierung des Herzogs von Benevent, der mit einer Kriegsgefangenen drei Kinder hat, zum vir bellicocissimus et ubique insignis), $180 \mathrm{f}$. (Waffenhilfe durch die Beneventaner, Versöhnung durch Friedenskuss), 185-187 (Lob der Treue des befreundeten Königs, Scheinflucht, Kampfesvorbereitung durch Instruktion der Kämpfer, nächtlicher Überfall auf das Lager der Franken, Angriff der Byzantiner über See, Prophezeiung des 
nur stellenweise eine größere Trennschärfe auf. Die Plünderung Roms und insbesondere die Schändung des in eine christliche Kirche umgewandelten Pantheons, wozu der Befehl des Kaisers und die griechische Gier die Byzantiner veranlasst hätten, sollen zur Ermordung des Kaisers Konstans, als er sich in Syrakus gerade ins Bad begeben habe, geführt haben ${ }^{175}$. Zwei inserierte Schreiben des Papstes Gregor des Großen an Theudelinda und ihren Gemahl, den Langobardenkönig Agilulf, sowie der abschließende Lobpreis des Chronisten auf den letzten Langobardenkönig Liutprand lassen immerhin eine gewisse Beeinflussung durch die augustinische Friedensethik erkennen ${ }^{176}$. Die zahlreichen gewalttätigen Auseinandersetzungen, in die das Langobardenreich im Verlauf seines Bestehens verstrickt war, lassen die "Historia Langobardorum" nichtsdestoweniger in weiten Teilen als eine Kriegsmonographie erscheinen.

Belisar, der im Auftrag des gerechten Kaisers Justinian im Mittelmeerraum eingesetzt war, erscheint beispielsweise als Sieger über zahlreiche Völker von den Persern über die Wandalen (und mittelbar auch über die Mauren) bis hin zu den Goten. Er habe deshalb zu Recht die ehrenden Beinamen Alamannicus, Gothicus, Francicus, Germanicus, Anticus, Alanicus, Wandalicus und Africanus erhalten ${ }^{177}$. Sein Nachfolger, der Eunuch Narses, verlor hingegen in Italien sein Leben, weil er nicht nur pervers, sondern auch geldgierig war. Sein Kriegsbündnis gegen die Goten soll im Übrigen die Langobarden dazu veranlasst haben, aus Pannonien nach Italien einzuwandern. Ihr Zug wird dabei mit ähnlichen Wendungen geschildert wie der

Untergangs des Langobardenreichs), 189 (Schlachtengedenken), 192-195 (Lohn für Verbündete, innere Unruhen als Bürgerkrieg, viertägige Schlacht, Plünderung und Brandschatzung der Hunnen führen zum Seitenwechsel des Langobardenkönigs Grimuald), 194 f. (Lagerabmessung, Erschrecken führt zur Flucht des Feindes), 196 f. (Schleifung und Aussiedlung der Bewohner von Oderzo, Ansiedlung einer auswärtigen Völkerschaft), 198 (Asylantenschicksal), 200 (Freundestreue wichtiger als Herrschaftswunsch), $201 \mathrm{f}$. (Befestigung einer Insel zur Verteidigung, gegenseitige Beschimpfung der Feinde), 205 f. (Kleriker opfert sich im Zweikampf an Stelle des Königs zur Wahrung des Schlachtenheils, Körper des in der anschließenden Schlacht unterlegenen gegnerischen Königs wird enthauptet, seiner Glieder beraubt und in einen Fluss geworfen, während der Held ein ehrenvolles Grab erhält), 219-222 (Errichtung eines Klosters auf dem Schlachtfeld, Gefangennahme eines Kinderkönigs, Hinweis auf Belagerungsmaschinen, Blendung und Enthäutung eines Konkurrenten des Königs), 223 f. (das Übel der Streitsucht), 224 (Gefangenenbefreiung), $227 \mathrm{f}$. (Schlacht gegen die Bajuwaren), 232-234 (Kampf junger Männer gegen die Slawen, Araberstürme in Spanien, Aquitanien, Gallien, Konstantinopel und an der Donau), $238 \mathrm{f}$. (innere Rebellion); zum Zweikampf: Wolfgang Schild, (Art.) Zweikampf. In: LMA, Bd 9, München, Zürich 1999, Sp. 723 f.

175 Paulus [Diaconus], Historia Langobardorum V 11 (wie Anm. 173), S. 191.

176 Ebd., IV 8 f. V 58, S. 146-149, 240-242. Die wohl auf einer der beiden neueren Ausgaben beruhende österreichische Internetfassung der »Historia Langobardorum « ergänzt nach dem Hinweis auf die Zusammenarbeit zwischen Karl dem Großen und Liutprand zu den in Buch V 54 geschilderten Auseinandersetzungen der Langobarden mit den Byzantinern in Italien nach petere compulerunt folgenden Absatz: Multa idem regnator contra Romanos bella gessit, in quibus semper victor extitit, praeter quod semel in Arimino eo absente eius exercitus caesus est, et alia vice, cum aput vicum Pilleum, rege in Pentapoli demorante, magna multitudo horum qui regi munuscula vel exenia vel singularum ecclesiarum benedictiones deferebant, a Romanis inruentibus caesa vel capta est. Rursus cum Ravennam Hildeprandus, regis nepos, et Peredeo Vicentinus dux optinerent, inruentibus subito Veneticis, Hildeprandus ab eis captus est, Peredo viriliter pugnans occubuit.

177 Ebd., I 25, S. 72. 
Auszug von Moses und dem Volk Israel aus Ägypten ${ }^{178}$. Der Meuchelmord am König, zu dem die Königin den Waffenträger Helmichis veranlasste, und das verräterische Treueversprechen, dass beide dem byzantinischen Präfekten Longinus leisteten, kosteten sie erwartungsgemäß das Leben. Der tapfere Peredeus, den die Königin zunächst verführt hatte, soll hingegen als Todeskandidat, der für den Zirkus in Konstantinopel bestimmt war, wie Samson in der Löwengrube gegen seine Gefängniswärter gekämpft haben. Dem anschließend zum Langobardenkönig erhobenen Adligen Cleph war zwar mit dem Schwert gegen die Byzantiner mehr Erfolg beschieden als seinem Vorgänger. Er starb jedoch, weil ihn ein junger Mann aus seinem Gefolge überraschend mit dem Schwert erstach. Die Geldgier veranlasste gleichwohl die Byzantiner in der nachfolgenden Zeit zu Tributen an die Langobarden $^{179}$. Die Deutungsmuster Geldgier, Perversität, Gewaltherrschaft und Kirchenschändung, welche mit den Tugenden der Freigebigkeit, Keuschheit, Friedfertigkeit und Frömmigkeit kontrastiert werden, prägen auch die weitere Darstellung der byzantinischen Kaiser, Heerführer und Militärbeamten bei Paulus Diaconus $^{180}$. So wird etwa der byzantinische Kaiser Maurikios als »überaus nützlich für das öffentliche Wohl « bezeichnet, habe er doch "oft im Kampf gegen die Feinde den Sieg errungen ${ }^{181}$. Der verräterische Patricius Gregorius soll hingegen Taso, dem Sohn des Langobardenherzogs Gisulf, versprochen haben, ihn nach alter Sitte durch Bartschur als eigenen Sohn anzunehmen. Als Taso mit seinem Bruder Cacco in der Stadt Oderzo eingetroffen war, ließ der Patricius stattdessen die Stadt verschließen, beide Heranwachsenden, die sich zur Flucht wandten und dabei tapfer wehrten, ergreifen und endlich enthaupten. Den um seines Bartes beraubten Kopf des Taso ließ er dann gleichsam als Beleg dafür, dass auch ein Byzantiner sein Wort hält, an die Langobarden übersenden ${ }^{182}$. Der Chronist zeichnet ein dazu konträres Bild von der Tätigkeit des römischen Patricius Dagisteus im Jahre 565. Er gilt nicht nur als siegreicher und tapferer Heerführer des Narses, sondern auch als fromm, katholisch, freigebig und Gott ergeben, sodass ihm dieser den verdienten Sieg über die Goten schenkt ${ }^{183}$.

178 Ebd., II 1-5. 7-9. 11, S. 84-93.

179 Ebd., II 28-31, S. 104-109.

180 Ebd., III 11 f. 15. 17. IV 26. 34. 36. 38. 42. 49 f. V 6. 11-13. 27 f. VI 12. 31 f., S. 118-124, 156, $160 \mathrm{f} ., 169,172-174,186 \mathrm{f} ., 190-192,196,217,225 \mathrm{f}$.

181 Ebd., IV 26, S. 156.

182 Ebd., IV 38, S. 167; vgl. ebd., II 42, S. 169, wonach die Byzantiner einem langobardischen Königssohn mit einem Hieb den Verstand rauben. Die Langobarden scheinen im Laufe der Zeit auch römisches Aussehen und Sitten übernommen zu haben. So soll die Königin Theudelinda um 600 den ehemaligen Palast der Goten in Ravenna erneuert haben. Gemälde, die die historischen Taten der Langobarden zeigten, ließen nach Aussage des Chronisten erkennen, wie sich die Langobarden ehemals den Kopf rasiert und welche Kleidung sie getragen hätten. Sie sollen sich nämlich den Kopf bis zum Hinterhaupt kahlgeschoren haben, wobei sie sich die Haare im Gesicht nur bis zum Mund entfernten, während sie sie an der Stirn und wohl auch am Kinn beibehielten. Die Kleidung, die vorher ähnlich wie bei den Angelsachsen aus lockerer Wolle bestanden habe, sei in späterer Zeit länger und in verschiedenen Farben eingefärbt worden. Die Stiefel, die ehemals bis auf eine Zehe offen waren, seien ursprünglich mit Schlingen zugeschnürt worden. Später aber hätten die Langobarden begonnen, stattdessen Stiefelschäfte zu benutzen, über die sie beim Reiten nach römischer Gewohnheit gamaschenartige Beinkleider und den Umhang gelegt hätten; ebd., IV 21 f., S. 154 f.; ähnlich ebd., V 33, S. 198, wonach König Rother zwar glatzköpfig war, aber einen langen Bart trug. Nach ebd., I 8, S. 90, lagen die frühen Langobarden auf den Fellen von Auerochsen zu Tisch.

183 Ebd., II 3, S. 85 f. 
Waffenstillstände und Kriegsbündnisse mit den Franken, Awaren, Sachsen und Slaven sowie zwischen den beiden eigentlichen Kriegsparteien ${ }^{184}$ bestimmen genauso das Geschehen wie systematische Stadteroberungen ${ }^{185}$ bzw. Land- ${ }^{186}$ und Seegefechte. Hin und wieder finden sich sogar konkrete Hinweise auf Geiselnahmen ${ }^{187}$, die geostrategische Lage als Voraussetzung für eine bestimmte Art der Kriegführung ${ }^{188}$, den Einsatz von Belagerungsmaschinen ${ }^{189}$, die multiethnische $\mathrm{Zu}$ sammensetzung eines Heeres ${ }^{190}$ oder die ungerechtfertigte Tötung eines Abgesandten $^{191}$. Ein schönes kulturgeschichtliches Detail besteht in der Aussage, dass die Verwandten eines Mannes, der im Krieg oder auf andere Weise ausgelöscht wurde, innerhalb eines ansonsten leeren Grabes eine Stange aufrichten, an deren Spitze eine hölzerne Taube aufgehängt wurde. Sie blickte in die Richtung, wo der Geliebte gestorben war, damit jeder wisse, in welcher Gegend der Verstorbene eigentlich ruhte ${ }^{192}$. Eine besondere Rolle scheint für Paulus Diaconus die Schlacht, bei der im Jahre 663 der Sohn des Langobardenkönigs Grimuald den ad hoc bestellten byzantinischen Heerführer Saburrus bei Forino besiegte, gespielt zu haben. Saburrus soll nämlich in Neapel leichtfertig 20000 Soldaten beim Augustus erbeten haben, um die Langobarden in der Schlacht zu besiegen. Auch der Königssohn Romuald habe mit dem Hinweis auf die Aussicht, den eigenen Ruhm durch einen Sieg zu erhöhen, seinen Vater um ein Truppenkontingent ersucht. Er unterteilte dieses dann in vier kleinere Verbände, welche auf ein Hornsignal hin über die überraschten Feinde herfielen. Als es dann in der eigentlichen Schlacht, bei der sich die Schlachtreihen beider Gegner gegenüberstanden, auch noch dem Lanzenträger Amalongus glückte, das eigene Heerzeichen gegen ein angreifendes "Griechlein « zu verteidigen, und er den Kopf des Besiegten auf seine Lanze steckte, soll das byzantinische Heer so von Furcht ergriffen worden sein, dass es sofort die Flucht aufnahm. Die Schilderung endet mit dem Kommentar des Chronisten:

"So hat also Saburrus, der dem Kaiser eine Siegestrophäe der Langobarden versprochen hatte, diesem, als er mit Wenigen zurückkehrte, nur Schande eingetragen. Romuald aber kehrte, nachdem er den Sieg über die Feinde errungen hatte, im Triumph nach Benevent zurück, hatte er doch dem Vaterland Freude und allen die Sicherheit, von der Furcht vor den Feinden befreit zu sein, gebracht ${ }^{193}$."

185 Ebd., V 7-11, S. 187-192.

186 Ebd., III 29. IV 45, S. 133, $170 \mathrm{f}$.

187 Ebd., IV 20. 28, S. 153 f., 157 f.

188 Ebd., II 9, S. $90 \mathrm{f}$.

189 Ebd., V 7 f., S. $188 \mathrm{f}$.

190 Ebd., II 26, S. 103.

191 Ebd., V 8. 27, S. 189 f., 196.

192 Ebd., V 34, S. 199.

193 Ebd., V 10, S. 189 f. 


\section{Von den Römern zu den Karolingern - ein Schlussresümee}

»Dies sind die Kriege, welche der großmächtige König während der siebenundvierzig Jahre, die er regierte, in verschiedenen Ländern mit der größten Einsicht und durchaus glücklich geführt hat. In ihnen hat er das Reich der Franken, das er nach seinem Vater schon groß und mächtig übernommen hatte, so herrlich erweitert, dass sein Umfang fast verdoppelt ward [...] So war er, das steht fest, als Hüter, Mehrer und zugleich Ordner des Reiches [...] Doch ließ er von allen Völkern unter seiner Herrschaft das noch nicht aufgeschriebene Recht zusammenstellen und schriftlich niederlegen ${ }^{194}$."

Mit diesen Worten, die fast an das eingangs angeführte Vergilzitat erinnern, charakterisiert Einhard die Herrschaft Karls des Großen. Die »Vita Karoli magni« besteht genau zu einem Drittel aus den Kriegstaten des Frankenkönigs und ersten abendländischen Kaisers. Die beiden anderen Drittel kennzeichnen nach dem Vorbild des spätrömischen Kaiserbiographen Sueton die Herkunft, die Lebensweise und das staatsmännische Wirken von Karl dem Großen. Wenn Einhard hervorhebt, dass sich der Frankenkönig beim Essen mit Vorliebe nicht nur die Lieder der Alten, sondern auch Abschnitte aus dem "Gottesstaat" des Augustinus habe vortragen lassen ${ }^{195}$, unterstreicht das die Bedeutung, die die zweigeteilte Weltordnung des Apostels Paulus und vermutlich auch die Lehre vom Frieden als letztem Ziel des Krieges für den Frankenkönig besaßen. Einhard scheint diese Einstellung geteilt zu haben, denn sein »Leben des großen Karl « gilt als erste mittelalterliche Biographie eines Laien aus laikaler Perspektive ${ }^{196}$. Obgleich sich Karl der Große in der Sicht Einhards von den Byzantinern als eigentlichen Römern abzusetzen suchte ${ }^{197}$, übernahm er von ihnen Elemente aus der spätrömischen Kriegführung. Dazu zählten nicht nur die Verteidigung der Seegrenzen durch eine Befestigung der Häfen, eine Stationierung von Kriegsschiffen ${ }^{198}$ und der Seekrieg ${ }^{199}$, die Sicherung der Landgrenzen durch die Aufstellung von Grenztruppen ${ }^{200}$ und Feldzüge ins Feindesland $^{201}$, sondern auch einige Feldschlachten, die Umsiedlung besiegter Völkerschaften ${ }^{202}$, Waffenstillstände ${ }^{203}$, Friedensverhandlungen ${ }^{204}$ und Kriegsbündnis-

194 Ebd., 15. 18. 29. Hrsg. und übers. von Rudolf Buchner, Darmstadt 1974 (= AusgQ, 5), S. $182 / 183-184 / 185,188 / 189,200 / 201$.

195 Ebd., 24, S. 194/195-196/198.

196 Brunhölzl, Geschichte, Bd 1 (wie Anm. 90), S. 318-320.

197 Einhard, Vita Karoli [Prologium]. 16. 23. 25 f. 28-30 (wie Anm. 192), S. 166/167 (ironische Selbstbezeichnung Einhards als homo barbarus), 184/185-186/187 (freundschaftliche Kontakte mit Byzanz), 194/195 (Ablehnung römischer Kleidung), 196/197 (unzureichende Kenntnisse der griechischen Sprache, aber flüssige Beherrschung des Lateinischen bei Karl dem Großen), 196/197-202/203 (Spolien aus Rom und Ravenna, Karls Reserve gegen die Kaiserkrönung in Rom, Förderung der Rechtsaufzeichnungen der Barbaren, nichtrömische Mitkaiserkrönung seines Sohnes); zum Verhältnis zwischen Karl dem Großen und Byzanz: Classen, Romanum gubernans imperium (wie Anm. 65); Classen, Karl der Große (wie Anm. 65).

198 Einhard, Vita Karoli 17 (wie Anm. 197), S. 186/187-188/189.

199 Ebd., 14, S. 182/183.

200 Ebd., 9, S. 176/177.

201 Ebd., 11-13, S. 178/179-182/183.

202 Ebd., 7 f., S. 173/174-176/177.

203 Ebd., 10, S. 178/179.

204 Ebd., 17, S. 186/187-188/189. 
$\mathrm{se}^{205}$. Karls eigentliches Kriegsziel ist ebenfalls als römisch anzusprechen. Es bestand nach Einhard (wie nach anderen Quellen) in der Ausdehnung des eigenen Territoriums durch strategisch sorgfältig geplante und wirksam durchgeführte Eroberungskriege ${ }^{206}$.

Als römische Bestandteile der Kriegführung, welche in den weiter oben behandelten Quellen immer wieder hervorgehoben werden, ist außerdem an die lokale Rekrutierung von Soldaten nach verschiedenen äußeren und inneren Kriterien, den regelmäßigen Drill, das Aufschlagen von Lagern, den Einsatz von Belagerungsmaschinen, das Auskundschaften des Feindes, Spionage, Kriegslisten, die Scheinflucht, Überraschungsangriffe aus dem Hinterhalt und das Aufstellen in Schlachtreihen als taktische Elemente sowie an die Berücksichtigung geographischer und logistischer Gegebenheiten bei der Planung und Durchführung von Feldzügen, das Aufteilen des Heeres im mehrere Säulen, die unter getrenntem Kommando standen und einander ergänzende taktische Aufgaben erfüllten, sowie den Wechsel zwischen persönlicher Beteiligung des Oberkommandierenden am Kriegszug und dem Einsatz von militärischen Fachleuten, der befristet oder an einen Auftrag gebunden war, als strategische Elemente zu erinnern. Die deditio blieb bis in die Karolingerzeit hinein Handlungsnorm bei der Unterwerfung von Städten oder Völkerschaften ${ }^{207}$. Der Triumphzug ist ein Element, das das Abendland im früheren Mittelalter durch den Austausch mit Byzanz beibehalten hat. Größere Umbrüche sind hingegen im westlichen Europa bei der Größe der stehenden Heere, dem Einsatz von Karten zur Orientierung, der Nutzung von Steinstraßen zur Fortbewegung, der geplanten Befestigung von Städten, der Unterbringung, Ernährung und Entlohnung der Soldaten sowie dem Einsatz von Kriegsschiffen zum Angriff zu beobachten. Die Stellung von Geiseln ${ }^{208}$ scheint demgegenüber ein Moment zu sein, das sich in der frühen Kaiserzeit aus dem Umgang der Römer mit Kriegsgefangenen und der wilden Geiselnahme durch die Barbarenvölker entwickelt hat. Auf römischen Einfluss ging dabei wohl die Stärkung des Vertragscharakters einer Geiselstellung zurück. Der Zweikampf wurde schon seit der Homer'schen »Illias «, dann aber auch in christlichen (Kampf der Tugenden und Laster bei Prudentius) und wanderzeitlichen Quellen (Paulus Diaconus, Heldenlieder) als legitimes Mittel der Kriegsentscheidung empfunden. Das kirchliche Asyl, das sich seit dem ausgehenden 4. Jahrhundert auf der Grundlage des römischen Sakralrechts herausgebildet hatte, war offenkundig eine Antwort auf die häufigen Übergriffe marodierender Soldaten auf Menschen und Kirchengut. Auch die Bewaffnung unterlag längerfristigen Veränderungen, an deren Ende schwer bewaffnete Panzerreiter als entscheidendes Moment der Kriegführung standen. An diesen Beispielen wird auch eine allmähliche Umprägung der Kriegsethik deutlich, die einen tiefgehenden sozialen und mentalen Wandel voraussetzte und erst im Zeitalter der Kreuzzüge mit dem Idealbild des miles Christi zum Abschluss kam. Die Karolingerzeit zeichnet sich im Rahmen dieser Entwicklung gegenüber dem früheren Mittelalter durch eine größere gegenseitige Annäherung der beiden ordines der Beter und Kämpfer aus. Ein weiterer Aspekt dieser Entwicklung liegt in der erst in der späten Salierzeit durchgesetzten Ableh- 
nung des Kriegsdienstes hoher Kleriker. Immerhin finden sich schon im früheren Mittelalter zahlreiche Hinweise auf die Tätigkeit von Bischöfen als Vermittler zwischen zwei Kriegsgegnern. Die Bewohner des lateinischen Europa gerieten, wie es auch an Hand der deditio und des Triumphzugs deutlich wurde, vor allem durch ihre Begegnungen mit Byzanz mit der römischen Kriegführung in Kontakt, auch wenn diese Kriegführung im griechischen Osten zahlreiche Abwandlungen, welche nicht zuletzt durch die jahrhundertelangen Auseinandersetzungen mit den Persern und den Arabern ausgelöst wurden, erfahren hatte.

Es kann daher nicht überraschen, wenn die Chroniken aus dem nördlichen Mittelmeerraum, in dem der Kontakt mit Byzanz an der Tagesordnung war, für militärgeschichtliche Einzelheiten, die an die Römer erinnern, besonders aussagekräftig sind. Diese Feststellung gilt für Cassiodor, Jordanes, Hydatius und Isidor genauso wie für Gregor von Tours, Fredegar und Paulus Diaconus. Im Falle der "Historia Wambae", die einen Feldzug beschreibt, spricht vieles sogar für eine Bewertung als Kriegsmonographie, das heißt als eine Quelle, deren Hauptthema kriegerische Auseinandersetzungen bilden. Auch die gerade genannten Volksgeschichten (origines gentium) und die Karlsbiographie Einhards weisen entsprechende Merkmale auf. Fredegar setzte sich sogar ausdrücklich zum Ziel, die Taten der Könige und die Kriege der Völker zu schildern. Die Beschreibungen bei Gildas und Beda Venerabilis erscheinen demgegenüber fast antiquarisch. Ihr eigentlicher Quellenwert besteht in den Deutungsmustern, mit deren Hilfe beide Chronisten die römischen Aspekte der eigenen Vergangenheit (und hierbei auch die kriegerischen Momente der Römerzeit) interpretieren. Eine weitere Gemeinsamkeit der behandelten Texte liegt in ihrem didaktischen Gebrauch zur Ermahnung und Warnung von König und Hof. Die Benutzung von Quellen als Fürstenspiegel, die schon für Isidor, Julian von Toledo, Beda und Paulus Diaconus vermutet wird, wurde dann in der Karolingerzeit geradezu zum Kennzeichen einer ganzen Epoche. Sie erstreckte sich dabei auf so unterschiedliche Gattungen wie Erziehungstraktate, Hofordnungen, Tugendlehren, Briefe, Gedichte, Heldenlieder, Kartenzeichnungen auf Tischplatten, Wandbemalungen in Königspfalzen, Psalter- und Bibelillustrationen oder die hier nicht behandelten Heiligenviten. Die Karolinger bedienten sich auch für die Schilderung der Vergangenheit mit Vorliebe solcher Quellen, die der eigenen Wahrnehmungsweise und den eigenen Gebrauchsbedürfnissen (im vorliegenden Fall der Deutung des Krieges im Rahmen der Didaxe) entgegenkamen. Diese Tendenz gilt auch für den Umgang mit den militärgeschichtlichen Quellen der Römer. Dazu zählen etwa die »Epitome rei militaris « des Vegetius, die anonyme "Notitia dignitatum « und die "Strategemata « des Frontinus. Eine entsprechende Untersuchung der Benutzung der kriegshistorischen »Klassiker « wurde bisher vor allem im Falle Ciceros unternommen, da sich seine Definition und seine ethische Bewertung des Krieges über Ambrosius, Augustinus und Isidor bis weit in die Neuzeit hinein ausgewirkt haben. Die Beobachtung, dass seine Spätschrift $» D e$ officiis « selbst eine Art von Fürstenspiegel bildet, lässt sich durch den Hinweis auf die pädagogische Ausrichtung der Abhandlungen "De officiis clericorum " des Kirchenvaters Ambrosius und »Contra Faustum《 des Kirchenvaters Augustinus sowie der "Etymologien « des Isidor von Sevilla fruchtbringend ergänzen. Die Benutzung der "Äneis" zur Kennzeichnung römischer Kriegstaten setzt hingegen erst bei den Merowingern spürbar ein. Parallel dazu entstand ein festes Ensemble von historiographischen Standardtexten, auf das sich dann beinahe alle Geschichtsschreiber des werdenden Abendlands stützten, wenn es um die Darstel- 
lung der römischen Vergangenheit ging. Dieses Ensemble besteht im Wesentlichen aus den drei großen christlichen Weltchroniken des 5. Jahrhunderts: Eusebius (in der Übersetzung des Rufinus), Hieronymus und Orosius, zuweilen aber auch aus den Fortsetzungen des Hieronymus durch Prosper von Aquitanien, Hydatius bzw. Johannes von Biclaro. Im 6. und 7. Jahrhundert kamen noch die »Zehn Bücher Geschichte " Gregors von Tours, die "Frankengeschichte" Fredegars sowie die "Weltchronik « und die »Kirchengeschichte« des Beda Venerabilis (und damit auch die Lamentatio »De excidio et conquestu Britanniae des Gildas) hinzu. In Italien wurde im 8. Jahrhundert auch das päpstliche Schrifttum (vor allem die Briefe Gregors des Großen und der »Liber Pontificalis«) und einzelne heidnische Quellen (wie etwa Eutropius) wahrgenommen.

Als erste Gruppe von Deutungsmustern des Krieges, die im Laufe der Zeit beinahe topischen Charakter annahmen, lassen sich die Stilisierungen römischer Feldherren zu Kriegshelden ansprechen, wie sie am Beispiel von Aëtius im westlichen und von Belisar im östlichen und südlichen Teil des Römischen Reiches deutlich werden. Auf »barbarischer « Seite entsprechen ihnen die Kennzeichnungen des Wandalenkönigs Geiserich sowie des Wisigotenkönigs Alarich als grausame, wenn auch sehr effiziente Kriegsherren. Der Ostrogotenkönig Theoderich I. erscheint demgegenüber als weiser Staatsmann, der in enger Verbindung mit den Römern agiert. Seine Charakterisierung wurde ähnlich wie die Beschreibungen der byzantinischen Kaiser und die Stilisierung Karls des Großen durch Einhard wohl vom stilistischen Vorbild der spätantiken Kaiserbiographien geformt. Ein weiteres Feld von Wahrnehmungsmustern, das ebenfalls fast wie eine Ansammlung von Stereotypen wirkt, betrifft die Charakterisierung des einfachen römischen Soldaten. Er gilt als seelisch ausgeglichen und körperlich standhaft, kriegstüchtig und kampferfahren, wohl diszipliniert, gut ausgebildet und überlegen bewaffnet, als loyal gegenüber dem Dienstherrn und als am Ruhm ausgerichtet. Der Barbarenkrieger erscheint demgegenüber als kühn, freiheitsliebend und seinem Anführer treu ergeben, aber auch als wild, grausam und der Beute verhaftet. Der Kirchenfrevel als ein häufiger Vorwurf, der an die arianischen Barbaren gerichtet war, bezeichnet gleichsam die Nahtstelle zwischen barbarischer Kriegführung und rechtgläubigem Leben. Er kam allerdings erst nach der erfolgreichen Christianisierung von Römern und germanischen Völkerschaften auf. Ein dritter Kreis von Deutungsschemata rankt sich um die auf Cicero fußenden Lehren von den verschiedenen Arten des Krieges und der richtigen Kriegführung. Die Unterscheidung zwischen inneren und äußeren Kriegen blieb bis weit in die Karolingerzeit hinein geläufig. Die ambrosianische Auslegung der Lehre von der Tapferkeit, wie sie sich bei Cicero findet, und das augustinische Modell vom Gerechten Krieg, das ebenfalls auf Cicero beruht, wurden hingegen im früheren Mittelalter nur ansatzweise berücksichtigt. Mit ihnen konkurrierte bei den schreibkundigen Klerikern nicht nur die alttestamentliche Vorstellung vom Heiligen Krieg bei den Klerikern, sondern auch die Bekämpfung von Apostaten und Häretikern als Aufgabe des frommen und gottgefälligen Herrschers. Die Gestalt der wehrhaften Roma stand dabei der Kirche, dem König und den Kämpfern wohl noch lange vor Augen. 


\section{Abstract}

The article concerning the question how the people in the earlier middle Ages did perceive the patterns and the operating modes of Roman warfare is especially based upon narrative sources for just in Merovingian times a fixed ensemble of chronicles was defined to show the Roman past to the contemporaries. The Carolingian clerks, however, favoured the use of sources belonging to military history as mirrors of princes.

Looking for some patterns of Roman warfare one can find in early medieval reports not only different descriptions of Roman and Barbarian commanders as war heroes or efficient war lords, but also really contrasting patterns referring to the attitudes shown by the simple Roman soldiers and their counterparts, the Barbarian fighters. The medieval chroniclers furthermore took over the concurrence between Biblical and Roman judgements belonging to the justification of war but there were some specific modifications. The Christian rulers, for example, from now on fought apostates and heretics and not Barbarian intruders who had constituted the essential adversary to the Roman Emperors. Not only in ancient poems but also in medieval chronicles the single combat was accepted as instrument of legal warfare. The providing of hostages probably resulted, on one hand, of the Romans' dealing with prisoners of war and, on the other hand, of the irregular taking of hostages by the Barbarians in the Imperial age. At the ending of the forth century the ecclesiastical asylum was obviously arisen of the Roman sacral law but it also seemed to be an answer to the frequent attacks foreign soldiers carried out to several people and different church goods. Indeed, the deditio stayed an accepted standard for the handing over of towns, tribes and individuals till nowadays. The triumph, however, was a special custom the Occidental nations took over from Byzantium.

Concerning strategy the chroniclers informed their public that someone following his Roman forerunners had to pay attention to geographic and logistic facts planning and carrying out a campaign, that the army if it were put into action, could be divided into several columns and commanded by different officers but it ought to be subordinated to one common destination. There could be an exchange from one commander to the other or not although the commandant stayed the same, and after his own decision he was personally able to fight in battle, too. Belonging to tactics the writers in the earlier middle Ages remembered that the soldiers should be locally recruited and regularly drilled, stratagems ought to be done, the camp has to be pitched every day, the enemy should be spied out by well trained observers, the siege supported by special machines, the battle line previously stipulated, the shock attack carried out by someone lying in ambush and the dummy flight suddenly brought into action. There were, however, longer-term changes belonging to the armament until the arrival of the well armoured cavalry in the Carolingian age. 